\title{
Integrated Strategic Planning of Global Production Networks and Financial Hedging under Uncertain Demands and Exchange Rates
}

\author{
Achim Koberstein, Detlef-Huebner-Chair in Logistics and Supply Chain Management, Goethe University Frankfurt, Germany, E-mail: \\ koberstein@wiwi.uni-frankfurt.de \\ Elmar Lukas, Chair in Financial Management and Innovation Finance, Otto-von-Guericke University Magdeburg, Germany, E-mail: \\ Elmar.Lukas@OvGU.de \\ Marc Naumann Decision Support and Operations Research Lab, University of Paderborn, Paderborn, Germany, E-mail: naumann@dsor.de
}

\begin{abstract}
In this paper, we present a multi-stage stochastic programming model that integrates financial hedging decisions into the planning of strategic production networks under uncertain exchange rates and product demands. This model considers the expenses of production plants and the revenues of markets in different currency areas. Financial portfolio planning decisions for two types of financial instruments, forward contracts and options, are represented explicitly by multi-period decision variables and a multi-stage scenario tree. Using an illustrative example, we analyze the impact of exchange-rate and demand volatility, the level of investment expenses and interest rate spreads on capacity location and dimensioning decisions. In particular, we show that, in the illustrative example, the exchangerate uncertainty cannot be completely eliminated by financial hedging in the presence of demand uncertainty. In this situation, we find that the integrated model can result in better strategic planning decisions for a risk-averse decision maker compared to traditional modeling approaches.
\end{abstract}

JEL classification: C61, M11, G62

Keywords: strategic production network planning, financial hedging, uncertainty, stochastic programming

Manuscript received July 9, 2011, accepted by Karl Inderfurth (Operations and Information Systems) June 7, 2013.

\section{$1 \quad$ Introduction}

Current economic developments, which are characterized primarily by the increasing globalization of markets, global networking by companies and significantly shorter product life cycles, provide major positioning and growth opportunities, but also significant risks for companies. While the availability of information has improved steadily due to modern communication technologies, the uncertainty and volatility of future developments has increased. Therefore, companies must consider uncertainty in their mid-term (tactical) as well as their long-term (strategic) planning. For companies that source, manufacture and sell on a global scale, strategic planning includes the design of an international supply chain network, consisting of suppliers, manufacturing plants of semi-finished and finished products, warehouses, transportation routes and sales markets. Strategic decisions about the number and the location of plants and warehouses, product-plant assignments, installed capacities and production technologies are often associated with large investments and typically cannot be reversed easily. Consequently, these decisions largely determine a company's tactical and operational leeway to react to uncertain future developments.

Quantitative strategic supply chain planning models account for the future consequences of strategic 
decisions by incorporating anticipation schemes for expenses and revenues at the tactical and operational levels, e.g., for transportation, production, inventory and the workforce. Two of the main sources of risk in global supply network design planning are uncertain exchange rates and demands. In this paper, we integrate an anticipation scheme for financial hedging and portfolio planning into a stochastic supply chain design model of the type described by Santoso, Ahmed, Goetschalckx, and Shapiro (2005) and Bihlmaier, Koberstein, and Obst (2009). We develop a multistage stochastic mixed-integer linear programming model, which includes discrete strategic decisions on facility location, product-plant assignment and capacity dimensions on the first time stage and operational production and logistics and financial decisions on subsequent time stages under uncertain exchange rates and demands. We analyze the consequences of the integrated anticipation of operational and financial hedging decisions for a risk-averse decision maker's optimal strategic planning solution in the context of an illustrative example.

The remainder of this paper is structured as follows: After reviewing the relevant literature in the fields of strategic production planning, real options valuation and financial hedging, we develop a multi-stage stochastic model that integrates financial hedging decisions into a traditional supply network design model. Special consideration is given to the modeling of two financial instruments, forward and option contracts, and the discretization of exchange-rate and demand uncertainty. Next, we present an illustrative example and study the impact of exchange-rate and demand volatility, investment expenses and interest rate spreads on strategic investment decisions. We conclude by summarizing our main results and by giving our perspective on future research.

\section{$2 \quad$ Literature review}

Models and methods for strategic production and distribution network design have been available since the early days of the field of operations research, in particular for facility and warehouse location and capacity dimensioning, taking into account a variety of linear and nonlinear cost factors associated with transportation, production and inventory (see, e.g., the reviews of Beamon 1998;
Aikens 1985; Vidal and Goetschalckx 1997; Owen and Daskin 1998; Klose and Drexl 2005). Geoffrion and Graves (1974) laid the foundations for many deterministic, network-flow-based strategic network planning models. The goal of their singleperiod mixed-integer model is to compute a minimum cost design of a multi-commodity production and distribution network using intermediate distribution centers. Computational tractability was achieved by using a customized solution algorithm based on Bender's decomposition principle. With growing computational capabilities of hardware and standard solution software for mixed integer programming problems, more requirements from industrial practice could be considered with an increasing level of detail. A typical example of a highly-detailed deterministic model is described in the article of Arntzen, Brown, Harrison, and Traffton (1995). The authors presented a multiperiod mixed-integer model for global supply chain planning. Their model includes detailed production, inventory and transportation planning and strategic decisions as product allocation with related fixed costs. The objective function includes the minimization of costs as well as weighted production and shipping times. A particular feature of the model is the focus on international aspects such as duties, import taxes or duty drawbacks. However, uncertainty in exchange rates or demands are not considered. The model is applied to a real-world example of a computer manufacturer. A second example is the more recent paper of Fleischmann, Ferber, and Henrich (2006), who presented a detailed multi-period mixed-integer model based on experiences at BMW (for details see Ferber 2005). Strategies for capacity and flexibility are optimized simultaneously, while taking into account a detailed representation of technical capacity stages and an anticipation of tactical workforce planning.

In the last decade, some researchers proposed stochastic programming models for supply network design as well as specially tailored solution algorithms and implementations for these kinds of models. MirHassani, Lucas, Mitra, Messina, and Poojari (2000) presented a multi-period, mixedinteger, two-stage stochastic program for capacity planning in supply chain design problems. The first stage comprises the opening and closing of plants and sets capacity levels. On the second stage, optimized decisions about production 
and distribution costs are made. Furthermore, the authors presented an effective acceleration technique for Bender's decomposition algorithm and demonstrated how well this approach can handle hundreds of scenarios for a particular case study. Alonso-Ayuso, Escudero, Garìn, Ortuño, and Pérez (2003) presented a two-stage stochastic program and a corresponding solution method for a similar supply chain design problem. Santoso, Ahmed, Goetschalckx, and Shapiro (2005) presented an accelerated Benders' Decomposition method for mixed-integer, two-stage stochastic programs for planning realistically scaled supply chain design networks. Utilizing a sampling strategy, they were able to handle a great number of scenarios. Their approach was successfully applied to strategic production network planning under uncertain demands in the automotive industry by Bihlmaier, Koberstein, and Obst (2009).

Another stream of literature focusses on the valuation of different kinds of operational flexibility in production networks. Jordan and Graves (1995) evaluated product flexibility to hedge against uncertain demands. Their numerical studies show that linking products and plants in a chain-like fashion is nearly as advantageous as a fully flexible strategy. This work provided a basis for a number of other researchers, e.g., Boyer and Keong Leong (1996), who included diverse setup costs incurred by simultaneous production of several products in a flexible plant, and Francas, Kremer, Minner, and Friese (2009), who evaluated the impact of demand dynamics caused by product life cycles. Chandra, Everson, and Grabis (2005) formulated a model for flexibility planning specifically for the automotive industry. Stochastic programming models have been used as a means to evaluate flexibility in manufacturing systems. Fine and Freund (1990) developed a stochastic programming model for optimizing product-flexible capacity under a finite number of possible demand realizations. Gupta, Gerchak, and Buzacott (1992) developed a similar model for finding optimal investment policies in the presence of fixed initial capacities. Chen, $\mathrm{Li}$, and Tirupati (2002) optimized the capacity of a flexible manufacturing system using stochastic programming, where the evolution of stochastic demand is represented using demand scenarios. None of the above works considers exchange-rate uncertainties.

A series of early papers by Jucker and Carl- son (1976), Hodder (1984), Hodder and Jucker (1985a), Hodder and Jucker (1985b) and Hodder and Dincer (1986) incorporated demand and price uncertainty, including exchange-rate uncertainty, in the context of an uncapacitated and, in the later papers, capacitated plant-location problem. An influential contribution was made by Huchzermeier and Cohen (1996) and Cohen and Huchzermeier (1999), who showed how operational flexibility can be utilized to hedge against demand and exchangerate contingencies and demonstrated that the adequate model-wise anticipation of operational hedging has a major effect on the underlying strategic decisions. They developed a stochastic dynamic programming model to evaluate the expected, discounted, after-tax profit for a set of predefined supply network configurations (strategy options), which determine the degree of a firm's manufacturing flexibility. Exchange rates are modeled as stochastic diffusion processes that take intercountry correlations into account. The authors demonstrated that operational hedging can create an effective hedge in the long term, while financial instruments can be more effective in the short term. Their approach is similar to ours as it provides a computational tool to analyze realworld supply and production networks of practical dimensions. However, our model offers several extensions: First, financial hedging instruments are explicitly considered in our model which is not the case in the dynamic programming approach. Thereby, tradeoffs between financial and operational hedging can be exploited directly and evaluated by the model. Second, network configurations and capacity dimensioning are represented as decision variables in our model, which enables the consideration of a much greater combinatorial complexity (in their case study, only 16 different configurations are considered). While switching costs could in principle be incorporated in our model, we do not consider them in this paper to keep the computational requirements controllable. Operational hedging practices have also been investigated analytically by several other authors (e.g. Cohen and Mallik 1997; Kouvelis 1999). Kazaz, Dada, and Moskowitz (2005) developed a two-stage stochastic program to evaluate two types of operational hedging under exchange-rate fluctuations: production hedging, where a firm deliberately produces less than the total demand, and allocation hedging, where the firm utilizes 
the option of not serving a certain market due to unfavorable exchange rates. The authors showed that both strategies are integral features of optimal policies. Financial hedging is not considered in their analysis. In the field of finance, the use of financial instruments such as forward and option contracts hedge against exchange-rate risks has been well known for a long time (cf., e.g., Briys and Solnik 1992; Froot, Scharfstein, and Stein 1993; Broll, Wahl, and Zilcha 1999; Chen, Lee, and Shrestha 2003). However, in these works, financial hedging is typically considered as totally independent of an underlying global manufacturing and distribution network, in spite of the intuitively apparent inter-dependencies. Cohen and Huchzermeier (1999) outlined the joint considerations of financial and operational hedging in the context of strategic supply chain planning as an important direction for future research. Nevertheless, this gap in the research literature received a greater amount of attention only recently. Chod, Rudi, and Van Mieghem (2010) investigated the relationship between financial hedging and product flexibility under uncertain demands. They showed that product flexibility and financial hedging can be both complements and substitutes depending on the prevailing demand correlations. Exchangerate uncertainty was neglected in their model. Zhu and Kapuscinski (2006) investigated operational versus financial hedging in a multinational riskaverse newsvendor framework under demand and exchange-rate uncertainty. They developed a dynamic programming formulation and showed in numerical experiments that operational hedging dominates financial hedging in terms of savings in most situations, that financial hedging can change the relationship between domestic and overseas capacities in some rare situations and that for a short planning horizon the level of savings heavily depends on the relative extent of the different hedging policies. Aytekin and Birge (2004) studied the use of financial hedging instruments versus the build-up of foreign production capacities for a simplified single-product firm operating in a home market and a foreign market under exchange-rate uncertainty only. They developed an analytic continuous time model to value the additional flexibility from building up capacity in foreign markets and deduce upper bounds on the value of additional capacities over all potential exchangerate volatilities. Ding, Dong, and Kouvelis (2007) showed in a rigorous analysis of stylized cases of up to two currency regions, markets, and production facilities, that a firm's optimal financial hedging strategy closely ties to its operational strategy and can have major effects on strategic supply chain decisions such as the location and the number of production facilities and the dimensioning of production capacities. Their work can be seen both as a theoretical foundation as well as a motivation for extending the traditional strategic supply chain planning models.

\section{$3 \quad$ Model description}

\subsection{Overview and notation}

The strategic single-period multi-commodity supply network design model of Santoso, Ahmed, Goetschalckx, and Shapiro (2005) serves as the basis for our integrated model. In this two-stage stochastic mixed-integer programming model, strategic investment decisions are represented by first-stage variables, and production and transportation quantities are represented by second-stage variables. Uncertainties in costs, demands and production rates are modeled as a random vector with a known discrete probability distribution. We extend this model with the following features:

- By adding time indices, we transform the single-period model into a multi-period model. For a typical strategic planning application, the planning horizon covers between five and fifteen years. Due to the strategic setting, we do not consider inventory balances among the time periods. We assume that there is no production during the first period. Strategic decisions and financial hedging decisions, which must be taken before the actual production begins, are assigned to the first time period.

- To consider the exchange-rate uncertainty, we build separate cash flows for each currency region. These cash flows are transformed into a reference currency and discounted over time.

- We integrate financial portfolio decisions over time on the purchase and execution of forward and options contracts on currencies to hedge against exchange-rate uncertainties. We assume a perfect financial market without transaction costs and arbitrage opportunities. 
- We capture uncertain exchange rates and demand over time in a scenario tree that is embedded in a multi-stage stochastic programming model. Each time period corresponds to a decision stage of the scenario tree. Investment and financial hedging decisions, which must be made before actual production begins, are represented by first-stage decision variables, which must be determined before uncertainty unfolds over time. Production and transportation quantities as well as the remaining financial hedging decisions are tied to certain nodes of the scenario tree. We state the model in implicit deterministic equivalent form. The decision variables are introduced for each scenario (= leaf of the scenario tree) and each time period, and the structure of a particular scenario tree is captured by adding non-anticipativity constraints (for an introduction to multi-stage stochastic programming see Birge and Louveaux 1997). We state some exemplary nonanticipativity constraints for the illustrative example that is analyzed in section 4 in the Appendix.

- The model maximizes a mean-risk objective function consisting of a weighted sum of the expected net present value of the profits and the conditional value at risk (CVaR) of the distribution of the scenario dependent net present values in the reference currency. The expected net present value is the difference between the discounted, scenario-dependent cash flows and the investment expenses.

In the remainder of the paper, we will use the following notation:

$$
\begin{aligned}
& \text { Sets and indices } \\
& S= \text { set of scenarios } s \\
& Z= \text { set of suppliers } z \\
& L= \text { set of processing facilities } l, \\
& \text { including manufacturing centers and } \\
& \text { machines, finishing facilities and } \\
& \text { machines, and warehouses } \\
& M= \text { set of markets } m \\
& N= \text { set of nodes } i \text { in the supply } \\
& \text { network (sometimes also indexed by } j \text { ), } \\
& N=Z \cup L \cup M
\end{aligned}
$$

$A=$ set of $\operatorname{arcs}(i, j)$ in the supply network, $A \subseteq N \times N$

$P \quad=\quad$ set of products $p$

$C=$ set of currencies $c$

$Z L=$ set of tuples $(z, c)$ which associate currency $c$ with supplier $z$,

$Z L \subseteq L \times C$

$L L=$ set of tuples $(l, c)$ which associate currency $c$ with processing facility $l$, $L L \subseteq L \times C$

$M L=$ set of tuples $(m, c)$ that associate currency $c$ with market $m$, $M L \subseteq M \times C$

\section{Input parameters}

$T=$ number of time periods

$\operatorname{prob}_{s}=$ probability of scenario $s$

$c_{l p}^{\text {build }} \quad=$ fixed initial investment, if processing facility $l$ is built for product $p$

$c_{l p}^{\text {operate }}=$ fixed operating expenses per time period, if processing facility $l$ has been built for product $p$

$q_{i j p t}=$ per-unit expenses of processing product $p$ at facility $i$ or purchasing product $p$ from supplier $i$ and/or transporting product $p$ on $\operatorname{arc}(i, j) \in A$ in period $t$

$\sup _{z p}=$ maximal supply of product $p$ provided by supplier $z$

$\operatorname{cap}_{l p} \quad=\quad$ maximal capacity of processing facility $l$ for product $p$

$d_{m p t s}=$ demand of product $p$ on market $m$ in time period $t$ and scenario $s$

price $_{m p t}=$ price of product $p$ on market $m$ in time period $t$

MHT = maximum duration of forward and option contracts

$e x r_{c t s}=$ exchange rate between the reference currency and currency $c\left[\frac{r e f}{c}\right]$ in time period $t$ and scenario $s$

$i r_{c}=$ interest rate of a riskless investment in currency $c$ 
$i^{r e f}=$ interest rate of a riskless

investment in the reference currency

$i^{\text {wacc }}=$ company specific interest rate used to compute discounted cash

flows (e.g., WACC: weighted average cost of capital)

fexr $_{\text {ctt's }}=$ hedged exchange rate between reference currency and currency $c$ for a forward contract which is signed in period $t$ and becomes effective in period $t^{\prime}$

$q_{c t t^{\prime}}^{\text {put }}=$ price of a put option between the reference currency and the currency $c$ that is purchased in time period $t$ and can be exercised in time period $t^{\prime}$ $q_{c t t^{\prime}}^{\text {call }}=$ price of a call option between the reference currency and the currency $c$ that is purchased in time period $t$ and can be exercised in time period $t^{\prime}$

$$
\begin{aligned}
& \text { Decision variables } \\
& y_{l p}=\text { binary variable: } \\
& 1 \text { if processing facility } l \\
& \text { is built for product } p \text {, } \\
& \text { o otherwise } \\
& x_{i j p t s}=\text { flow of product } p \text { on } \operatorname{arc}(i, j) \\
& \text { in time period } t \text { and } \\
& \text { scenario } s \\
& f_{c t t ' s}^{r e v}=\text { amount of revenues in } \\
& \text { currency } c \text { hedged by a } \\
& \text { forward contract that is } \\
& \text { signed in time period } t \\
& \text { and becomes effective } \\
& \text { in time period } t^{\prime} \\
& f_{c t t^{\prime} s}^{\text {exp }}=\text { amount of expenses in } \\
& \text { currency } c \text { hedged by a } \\
& \text { forward contract that is } \\
& \text { signed in time period } t \\
& \text { and becomes effective in } \\
& \text { time period } t^{\prime} \\
& \text { call ctt's }_{b}^{b}=\text { amount in currency } c \\
& \text { for which call options } \\
& \text { are purchased in } \\
& \text { time period } t \text { in scenario } s
\end{aligned}
$$

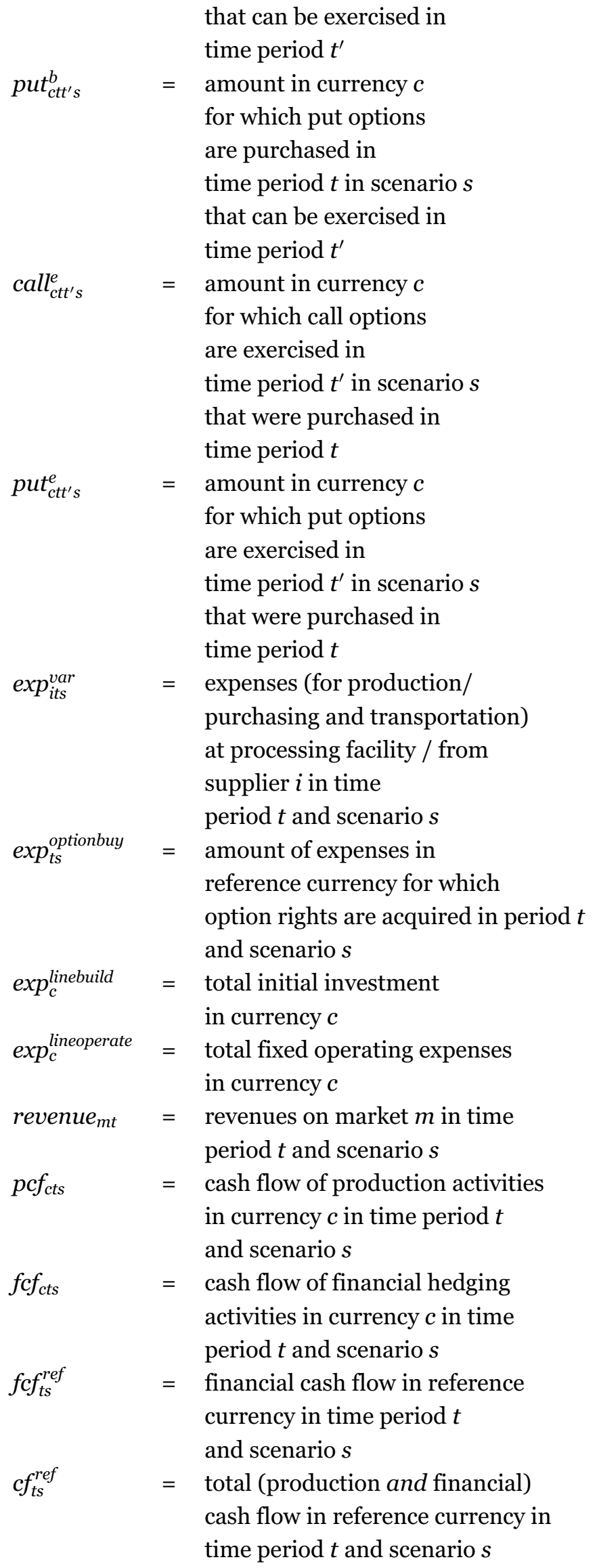

that can be exercised in time period $t^{\prime}$ 


$\begin{array}{ll}n p v_{s}= & \begin{array}{l}\text { net present value in } \\ \text { reference currency in } \\ \text { scenario } s\end{array} \\ \text { expected_npv }= & \begin{array}{l}\text { expected net present value } \\ \text { in reference currency }\end{array} \\ C V a R= & \begin{array}{l}\text { conditional value at risk in } \\ \text { reference currency for a } \\ \text { given probability } \alpha\end{array} \\ = & \begin{array}{l}\text { auxiliary dual variables } \\ \text { needed in the CVaR } \\ y_{0}, y_{s} \\ \text { formulation }\end{array}\end{array}$

\subsection{Basic production network design} model

The network design portion of our model resembles a classical multi-commodity network design formulation on the graph $G=(N, A)$ :
(1) $\sum_{i \in N} x_{i l p t s}-\sum_{j \in N} x_{l j p t s}=0$
$\forall l, p, t, s$
(2) $\sum_{l \in L} x_{\text {lmpts }} \leq d_{m p t s}$
$\forall m, p, t, s$
(3) $\sum_{l \in L} x_{z l p t s} \leq \sup _{z p}$
$\forall z, p, t, s$
(4) $\sum_{i \in N} x_{i l p t s} \leq \operatorname{cap}_{l p} \cdot y_{l p}$
$\forall l, p, t, s$
(5) $y \in Y \subseteq\{0,1\}^{\mathrm{L} \times \mathrm{P}}$
(6) $x_{i j p t s} \geq 0$
$\forall i, j, p, t, s$

Constraint set (1) assures the flow balance of the incoming and the outgoing product quantities for processing facilities. The demand satisfaction for each market is formulated by constraint set (2). If shortfalls are not permitted, then the constraint can be modified to equality. However, this modification can lead to feasibility problems in the presence of scenario-dependent demands. Constraint set (3) requires that the total flow of product $p$ from a supplier node $z$ cannot exceed the maximal supply sup ${ }_{z p}$ at that node. The product-dependent capacity constraints (4) mark a slight difference from Santoso's model, where different products can share a maximum capacity. While our formulation has greater combinatorial complexity due to its increased number of binary variables, our model more accurately represents a typical planning situation in our favorite application domain, the automotive industry. In this industry, enabling a production facility to simultaneously manufac- ture different products entails large investments, which must be considered in the objective function. If a certain product $p$ is processed at facility $l$, then the constraint set (4) requires that the respective indication variable $y_{l p}$ equals 1 . If facility $l$ is not built $\left(y_{l p}=0\right)$, then the constraint will force all flow variables $x_{i l p t s}=0$. Constraint (5) declares that the decision variables $y_{l p}$ are binary. The set $Y$ can include fixed opening $\left(y_{l p}=1\right)$ or closing $\left(y_{l p}=0\right)$ decisions. Constraint set (6) declares the flow variables as continuous and nonnegative. The following monetary components are formulated for the production-related portion of the model:

(7) $\exp _{i t s}^{v a r}=\sum_{(i, j) \in A} \sum_{p \in P} q_{i j p t} x_{i j p t s} \quad \forall i, t, s$

(8) revenue $_{m t}=\sum_{p \in P}$ price $_{m p t} d_{m p t} \quad \forall m, t$

（9） $\exp _{c}^{\text {linebuild }}=\sum_{(l, c) \in L L} \sum_{p \in P} c_{l p}^{\text {build }} y_{l p} \quad \forall c$

(10)

$$
\begin{aligned}
& \exp _{c}^{\text {lineoperate }}=\sum_{(l, c) \in L L} \sum_{p \in P} c_{l p}^{\text {operate }} y_{l p} \quad \forall c \\
& \text { (11) } p c f_{c t s}=\sum_{(m, c) \in M L} \text { revenue }_{m t} \\
& -\sum_{(i, c) \in L L \cup Z L} \exp _{i t s}^{\text {var }}-\exp _{c}^{\text {lineoperate }} \quad \forall c, t, s
\end{aligned}
$$

Constraint set (7) determines the expenses incurred by the purchasing, production and transportation functions for each processing facility/supplier in each time period and scenario. Likewise, constraint set (8) computes revenues. Note, that the currency of both sets of bookkeeping variables is determined implicitly by the associated supplier, processing facility and market. In the following, the sets $Z L, L L$ and $M L$ are used to identify which suppliers, processing facilities and markets belong to a certain currency region. The sum of all initial investment and operating expenses in a certain currency are calculated in constraint sets (9) and (10), respectively. In constraint set (11), cash flows induced by all operational production activities (excluding initial investments) in a certain currency region are computed.

\subsection{Modeling of financial instruments}

Our representation of financial hedging decisions is a simplified version of the model proposed by $\mathrm{Wu}$ 
and Sen (2000). We assume perfect financial markets and do not consider transaction costs. Furthermore, we make the following assumptions that largely coincide with those of Wu and Sen (2000):

- We only consider European options, which cannot be exercised before their due date.

- The financial instruments used in this model have a maximum lifetime of $M H T$ time periods and a minimum lifetime of one period. Note that in our strategic model, the time periods usually span from several months to a year.

- The outcomes of random variables are revealed sequentially over time, and their outcomes are observed only at the end of each time period.

- The purchase and the disposal of financial instruments can only take place at the beginning of each time period.

- The amounts of the options and forward contracts can be traded in fractions of a unit.

- We do not account for taxes in our model.

\subsubsection{Forward contracts}

Forward contracts are always signed between a currency $c$ and the reference currency. The period in which the forward contract is signed is denoted by $t$, and the period in which it takes effect is denoted by $t^{\prime}$. The variables $f_{\text {ctt's }}^{\text {exp }}$ are used to hedge the expenses (incurred by production, transportation and line operations) in currency $c$. These variables are equal to the amount of currency $c$ that is obtained by exchanging the reference currency in the time period $t^{\prime}$ at the hedged exchange rate exr $_{c t t ' s}$. Likewise, the variables $f_{c t t^{\prime} s}^{r e v}$ equal the negative amount of currency $c$ that is exchanged into the reference currency to hedge revenues of currency $c$. For clarity the revenues and the expenses are hedged independently in our model. Note that given the above interpretation, decision variables associated with forward contracts can only take values greater than zero for currencies other than the reference currency. We assume without loss of generality that the reference currency is denoted by subscript 1 and set the corresponding variables to zero:

(12) $f_{c t t ' s}^{r e v} \leq 0, f_{c t t^{\prime} s}^{e x p} \geq 0 \quad \forall c, 0 \leq t^{\prime}-t \leq M H T, s$

(13) $f_{1 t t^{\prime} s}^{r e v}=0, f_{1 t t^{\prime} s}^{e x p}=0 \quad \forall 0 \leq t^{\prime}-t \leq M H T, s$
The hedged exchange rate for forward contracts and futures $f$ exr $_{\text {ctt's } s}$ is calculated in a preprocessing step according to our assumptions as follows:

(14) $f e x r_{c t t^{\prime} s}=e x r_{c t s} \cdot e^{\left(i r^{r e f}-i r_{c}\right) \cdot\left(t^{\prime}-t\right)}$

$$
\forall c, 0 \leq t^{\prime}-t \leq M H T, s
$$

The consideration of forward contracts in the total cash flow of financial instruments is discussed below.

\subsubsection{Option contracts}

In our model, options always work between a currency $c$ and the reference currency. An option is purchased and can be exercised in time periods $t$ and $t^{\prime}$, respectively. As only European options are considered, an option cannot be exercised prior to its expiration. The maximum lifetime of an option is limited by $M H T$ time periods. Option contracts are then modeled as follows:

(15) call $_{c t t^{\prime} s}^{e} \leq$ call $_{c t t^{\prime} s}^{b} \quad \forall c, 0 \leq t^{\prime}-t \leq M H T, s$

(16) $\mathrm{put}_{c t t^{\prime} s}^{e} \leq p u t_{c t t^{\prime} s}^{b} \quad \forall c, 0 \leq t^{\prime}-t \leq M H T, s$

(17) call $_{\text {ctt's }}^{b} \geq 0$,

callctt's $\geq 0$,

put $t_{\text {ctt's }}^{b} \geq 0$,

put $e_{\text {ctt's }}^{e} \geq 0$

$$
\forall c, 0 \leq t^{\prime}-t \leq M H T, s
$$

The decision variables $p u t_{c t t^{\prime} s}^{b}$ and call ctt's $^{b}$ indicate the amount of currency $c$ in scenario $s$ for which puts and calls are bought in period $t$ that expire in period $t^{\prime}$. Thereby, separate hedging for revenues and expenses is possible. The decision variables $p^{\prime} t_{c t t^{\prime} s}^{e}$ and call $_{c t t^{\prime} s}^{e}$ indicate the exercised puts and calls in period $t^{\prime}$ that were bought in period $t$. Depending on the exchange rate changes between $t$ and $t^{\prime}$, an arbitrary fraction of options can be exercised in $t^{\prime}$. Constraint sets (15) and (16) guarantee that only options that were purchased in a previous time period can be exercised. Decision variables associated with option contracts can only take values greater than zero for currencies other than the reference currency. We assume without loss of generality that the reference currency is denoted by subscript 1 and set the corresponding variables to zero:

$$
\begin{aligned}
& \text { call }_{1 t t^{\prime} s}^{b}=0, \text { call }_{1 t t^{\prime} s}^{e}=0, \\
& \text { put }_{1 t t^{\prime} s}=0, \text { put }_{1 t t^{\prime} s}^{e}=0 \forall 0 \leq t^{\prime}-t \leq M H T, s
\end{aligned}
$$


Prices of call and put options per unit of currency $c, q_{c t t ' s}^{c \text { call }}$ and $q_{c t t^{\prime} s}^{\text {put }}$, respectively, are calculated in a preprocessing step according to a discrete version of the Garman and Kohlhagen model (Garman and Kohlhagen 1983):

(19) $q_{\mathrm{ctt} t^{\prime} s}^{\text {call }}=\frac{e x r_{c t s}}{e^{i r^{r e f}\left(t^{\prime}-t\right)}} \sum_{j=0}^{t^{\prime}-t}\left(\begin{array}{c}t^{\prime}-t \\ j\end{array}\right) p^{j} \cdot(1-p)^{\left(t^{\prime}-t\right)-j}$

$$
\begin{gathered}
\cdot \max \left(u^{j}(1 / u)^{\left(t^{\prime}-t\right)-j}-e^{\left(i r^{r e f}-i r_{c}\right)\left(t^{\prime}-t\right)}, 0\right) \\
\forall c, 0 \leq t^{\prime}-t \leq M H T, s
\end{gathered}
$$

$$
\begin{aligned}
& q_{c t t t^{\prime} s}^{p u t}=\frac{\operatorname{exr}_{r_{c t s}}}{e^{i r^{r e f}\left(t^{\prime}-t\right)}} \sum_{j=0}^{t^{\prime}-t}\left(\begin{array}{c}
t^{\prime}-t \\
j
\end{array}\right) p^{j} \cdot(1-p)^{\left(t^{\prime}-t\right)-j} \\
& \cdot \max \left(e^{\left(i r^{r e f}-i r_{c}\right)\left(t^{\prime}-t\right)}-u^{j}(1 / u)^{\left(t^{\prime}-t\right)-j}, 0\right) \\
& \forall c, 0 \leq t^{\prime}-t \leq M H T, s
\end{aligned}
$$

Here, $u$ designates the percentage change of the spot rate and $p$ denotes the risk-neutral probability of an up movement of the currency spot rate. For simplicity, we assume that the exercise price of an option is always equal to the forward exchange rate. We will describe the computation of exchange-rate volatility and option prices to generate a consistent scenario tree in greater detail in section 3.5.

In our model, the effects of forward and option contracts are taken into account in financial cashflows for each foreign currency and the reference currency. These cash flows for forward and option contracts are formulated in equation sets (22) and (23), respectively. The accounting variables $\exp _{t s}^{\text {optionbuy }}$ computed in constraint set (21) contain all expenses incurred by buying options in time period $t$ and scenario $s$.

(21) $\exp _{t s}^{\text {optionbuy }}=\sum_{c \in C} \sum_{t^{\prime}: 0 \leq t^{\prime}-t \leq M H T}\left(q_{c t t t^{\prime} s}^{\text {call }} \cdot\right.$ call $_{c t t^{\prime} s}^{b}$

$$
\left.+q_{c t t^{\prime} s}^{p u t} \cdot p u t_{c t t^{\prime} s}^{b}\right) \quad \forall t, s
$$

(22)

$$
\begin{aligned}
& f_{c} f_{c t^{\prime} s}=\sum_{t: 0 \leq t^{\prime}-t \leq M H T}\left(f_{c t t^{\prime} s}^{e x p}+f_{c t t^{\prime} s}^{r e v}\right. \\
& \left.+ \text { call }_{c t t^{\prime} s}^{e}-p u t_{c t t^{\prime} s}^{e}\right) \quad \forall c, t^{\prime}, s
\end{aligned}
$$

$$
\begin{aligned}
& f c f_{t^{\prime} s}^{r e f}=-\sum_{c \in C} \sum_{t: 0 \leq t^{\prime}-t \leq M H T}\left(f_{c t t^{\prime} s}^{e x p}+f_{c t t^{\prime} s}^{r e v}\right. \\
& \left.+c a l l_{c t t^{\prime} s}^{e}-p u t_{c t t^{\prime} s}^{e}\right) \cdot f e x r_{c t t^{\prime} s} \\
& -\exp _{t^{\prime} s}^{\text {optionbuy }} \quad \forall t^{\prime}, s
\end{aligned}
$$

\subsection{Objective functions}

3.4.1 Maximization of expected net present value

For clarity, the expected net present value is computed in several steps:

(24)

$$
\begin{aligned}
& c f_{t s}^{r e f}=\operatorname{exr}_{c t s}\left(\sum_{c \in C} p c f_{c t s}+\sum_{c \in C} f c f_{c t s}\right) \\
& +f c f_{t s}^{r e f}
\end{aligned}
$$

(25)

$$
\begin{aligned}
& n p v_{s}=\sum_{t=1}^{T} \frac{c f_{t s}^{r e f}}{\left(1+i r^{\text {wacc }}\right)^{t}} \\
& -\sum_{c \in C} \exp _{c}^{\text {linebuild }} \cdot \operatorname{exr}_{c 11}
\end{aligned}
$$

expected_npv $=\sum_{s \in S} p r o b_{s} \cdot n p v_{s}$

Total cash-flows in the reference currency are computed for each scenario and time period in the constraint set (24). Constraint set (25) determines the scenario-dependent net-present-values as the difference of the discounted net-present-values and the sum of the initial investment in the reference currency. The expected net present value over all scenarios is determined in constraint (26). At this point, we can state the complete model for expected value maximization as follows:

(27)

Maximize expected_npv

subject to constraint sets (1) to (12),

(15) to (17) and (21) to (26)

Note that we have not enlisted non-anticipativity constraints explicitly. These constraints are needed to take into account the timewise structure of decisions with respect to the given scenario tree. Often, non-anticipativity is taken into account implicitly by the solution algorithm (e.g., by the sampling method given by Wu and Sen 2000) or the modeling environment (e.g., see the SPInE environment by Valente, Mitra, Sadki, and Fourer 2009). We state some exemplary non-anticipativity constraints for the model instance that is analyzed in our case example in section 4 in the Appendix of this paper. 


\subsubsection{Minimization of risk and construction of the efficient frontier with respect to risk and profit}

To examine the effects of the integration of financial instruments, risk measures can be added to the optimization model and optimized in the objective function. In recent years, the conditional value at risk (CVaR) has become a widely accepted risk measure in the area of finance. Given a probability $\alpha$, the CVaR is defined as the conditional mean value of the worst $(1-\alpha) * 100 \%$ of losses/profits. The CVaR was first proposed by Rockafellar and Uryasev (2002). The authors also showed its computational tractability by representing $\mathrm{CVaR}$ as the optimum of a special minimization problem. It is well known that in the case of discrete finite distributions, CVaR optimization problems can be formulated as linear programming problems. To integrate CVaR into our model, we use the following dual formulation of Fábián (2008):

\section{Maximize $C V a R$ \\ subject to}

(29)

$$
C V a R=y_{0}-\frac{1}{1-\alpha} \sum_{s \in S} \operatorname{prob}_{s} y_{s}
$$

(30)

$$
y_{0}-y_{s} \leq n p v_{s}
$$

(31) $y_{s} \geq 0$

subject to constraint sets (1) to (12),

(15) to (17) and (21) to (26)

where $C V a R, y_{0}$ and $y_{s}$ denote $|S|+2$ additional continuous decision variables $\left(\mathrm{CVaR}\right.$ and $y_{0}$ are generally unbounded). In our illustrative example, we will construct the efficient frontier of nondominated solutions with respect to the expected net present value and the CVaR using the following combined objective function:

$$
\text { Maximize }(1-\lambda) \cdot \text { expected_npv }+\lambda \cdot C V a R
$$$$
\text { subject to constraint sets (1) to (12), }
$$$$
\text { (15) to (17), (21) to (26) }
$$$$
\text { and (29) to (31) }
$$

The parameter $\lambda$ controls the weight given to the optimization of the expected profit and the CVaR.
Therefore, $\lambda$ reflects the level of risk aversion of the decision maker. For $\lambda=0$ the objective function (32) coincides with the objective function (27), yielding the optimal solution with respect to the expected profit. For $\lambda=1$ it coincides with objective function (28), yielding the solution that maximizes CVaR. To construct the efficient frontier, the parameter $\lambda$ is iterated between 0 and 1 . We usually use a logarithmic scale for $\lambda$ to generate more solution points in the proximity of the optimal expected profit solution.

\subsection{Scenario generation}

In this section, we describe the modeling of exchange-rate and demand uncertainty. We start by modeling pure exchange-rate uncertainty by means of a binomial scenario tree. Then, in the second step, we incorporate the demand uncertainty. The consideration of exchange-rate uncertainty leads to a random factor for each currency region. We model the exchange rates as a geometric Brownian motion with constant volatility $\sigma^{E}$ (see Musiela and Rutkowski 1997 for further justification). How to represent multiple stochastic factors and processes by scenario trees has been the subject of intensive investigations (see $\mathrm{Wu}$ and Sen 2000 and the references therein). We discretize the stochastic processes by generating a binomial lattice as proposed by Cox, Ross, and Rubinstein (1979). The volatility $\sigma^{E}$ of a random factor is controlled by a constant $u^{E}$. Given the value $S_{0}$ of a random factor at a certain node in the scenario tree, two successors $S_{0} \cdot u^{E}$ and $S_{0} / u^{E}$ are created. The dependency of $u^{E}$ and $\sigma^{E}$ is given by the following equation (see, e.g., Hull 2003: p. 211ff.):

(33) $u^{E}=e^{\sigma^{E}}$

The probability $p^{u p}$ of a positive development, which means a multiplication with $u^{E}$, is determined as follows (see, e.g., Hull 2003: p. 211ff.):

(34) $p^{u p}=\frac{e^{i r^{r e f}-i r_{c}}-\frac{1}{u^{E}}}{u^{E}-\frac{1}{u^{E}}}$

The probabilities of an exemplary binomial tree for the case of 64 scenarios can be calculated as 
Figure 1: Scenario tree with 6 stages representing joint exchange-rate and demand uncertainty.

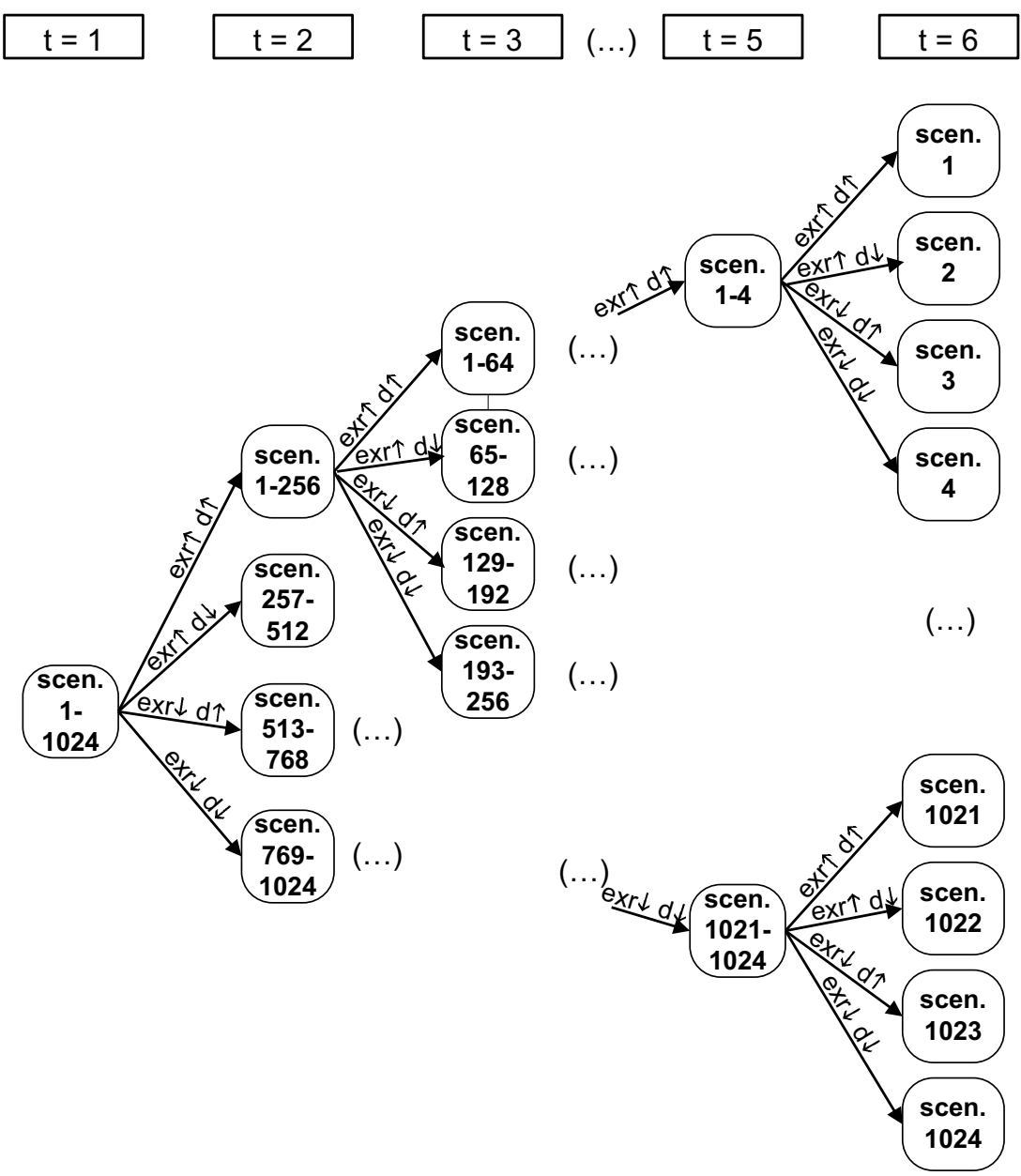

follows:

(35)

$$
\begin{aligned}
\operatorname{prob}_{s}= & \left(p^{u p}\right)^{1-(s \operatorname{div} 33)} \cdot\left(1-p^{u p}\right)^{s \operatorname{div} 33} \\
& \cdot\left(p^{u p}\right)^{1-(((s-1) \bmod 16) \operatorname{div} 8)} \\
& \cdot\left(1-p^{u p}\right)^{((s-1) \bmod 16) \operatorname{div} 8} \\
& \cdot\left(p^{u p}\right)^{1-(((s-1) \bmod 4) \operatorname{div} 2)} \\
& \cdot\left(1-p^{u p}\right)^{((s-1) \bmod 4) \operatorname{div} 2 \quad \forall s}
\end{aligned}
$$

To consider the uncertain demand, we incorporate demand development into the scenario tree. Figure 1 depicts the scenario tree used in our illustrative example in section 4 , which models joint exchange-rate and demand uncertainty. In this tree, each node contains four successors that represent two demand developments (up / down) for each exchange-rate development in such a way, that, for each time stage predetermined product demand levels $d_{m p t}$ yield as expected values. These demand levels can be utilized, e.g., to model life cycle developments. Technically, for an arbitrary node $i$ on stage $t$ of the scenario tree, the associated scenario-dependent demand value $d_{m p t s}$ is computed as $\Delta_{t}^{i} d_{m p t}$, where $\Delta_{t}^{i}$ represents the demand development in this node. For the successor-nodes of node $i$ this value is set to $\Delta_{t}^{i} \cdot u^{D}$ and $\Delta_{t}^{i} / u^{D}$. For the root-node, $\Delta_{0}^{1}$ is set to 1 . The constant $u^{D}$ is derived from the demand volatility $\sigma^{D}$ as $u^{D}=e^{\sigma^{D}}$. To consider up-and-down movements of demands with equal probability, the $p^{u p}$ constant has to be multiplied by a factor of 0.5 .

\section{Illustrative case example and results}

\subsection{Setting and goals}

In this section, we investigate a stylized case, which comprises a company that manufactures three 
products at a maximum of two production plants in two currency regions to satisfy the demand of its home market. Production capacity can be installed in discrete steps at the domestic plant or at the foreign plant. The exchange rates and product demands are assumed uncertain. We presume that the demand developments for the three different products are perfectly correlated and independent of exchange-rate fluctuations. The planning horizon spans over six time periods, which resulted in a scenario tree of 1024 scenarios (leafs). Note that no production takes place in the first planning period because it is reserved for investment and financial hedging decisions. In section 4.2, we provide a detailed description of the underlying data. In our analysis, we pursue the following goals:

1. In section 4.3 , we analyze the impact of joint exchange-rate and demand volatility on the interaction of operational and financial hedging, capacity and location decisions.

2. In section 4.4 , we analyze the impact of the level of investment expenses and fixed costs, on capacity dimensioning in particular.

3. In section 4.5, we analyze the impact of spreads between interest rates of the foreign and domestic currency regions.

4. In section 4.6, we compare traditional strategic planning procedures, which usually disregard financial planning, with our integrated approach.

Because the focus of this paper is not solution methodology, we will not conduct a thorough computational study in terms of model sizes and runtime. The model of the presented case example was implemented using a mathematical programming language (AMPL) and solved using IBM Cplex 12. The majority of the resulting model instances were solved in 10 minutes of runtime on a standard laptop computer.

\subsection{Setting and data}

Figure 2 displays the general setting described previously. The solid arcs (1) and (2) represent flows of goods produced in the foreign and domestic plant, respectively, and transported to the customers in currency region $\mathrm{C} 1$. The dashed arcs (3) and (4) depict financial flows, i.e., via arc (3)
Table 1: Expected product demands.

\begin{tabular}{lrrr} 
time & & & \\
period & P1 & P2 & P3 \\
\hline $\mathbf{1}$ & 0 & 0 & 0 \\
$\mathbf{2}$ & 330000 & 0 & 40000 \\
$\mathbf{3}$ & 330000 & 0 & 120000 \\
$\mathbf{4}$ & 270000 & 0 & 160000 \\
$\mathbf{5}$ & 200000 & 120000 & 180000 \\
$\mathbf{6}$ & 120000 & 240000 & 180000 \\
\hline
\end{tabular}

Table 2: Variable production expenses per unit.

$\begin{array}{lrrr} & \text { P1 } & \text { P2 } & \text { P3 } \\ \text { domestic plant* }^{*} & 7.0 & 12.5 & 17.0 \\ \text { foreign plant }^{* *} & 5.0 & 9.0 & 13.0\end{array}$

*: in thousand units of currency $C 1,{ }^{* *}$ : in thousand units of currency $\mathrm{C} 2$

the company covers production and transportation costs incurred in the foreign production plant, and arc (4) illustrates revenues earned by the company in the domestic market. Consequently, in this case, only processing costs incurred in the foreign plant are exposed to exchange-rate fluctuations, whereas expenses and revenues in the domestic currency region are not exposed to exchange-rate fluctuations.

Customer demands for the three products P1 - P3 are listed in Table 1. The demand figures represent different life-cycle situations, i.e., an ending life cycle for P1 and starting life cycles for P2 and $\mathrm{P}_{3}$. Variable production and transportation expenses are listed in Tables 2 and 3, respectively. Because we presume an initial exchange rate of 1.0 at the beginning of the planning horizon, data on expenses are directly comparable. We assume that foreign production is generally cheaper than domestic production, despite higher costs of transportation from the foreign production plant to the customer market. Table 4 shows the sales prices per unit in the domestic market. Profit margins

Table 3: Transportation expenses per unit from the production plants to the customer market.

\begin{tabular}{lrrr} 
& P1 & P2 & P3 \\
\hline from domestic plant* $^{*}$ & 0.20 & 0.22 & 0.25 \\
\hline from foreign plant $^{* *}$ & 0.80 & 1.00 & 1.20
\end{tabular}

*: in thousand units of currency $C 1,{ }^{* *}$ : in thousand units of currency $\mathrm{C} 2$ 
Figure 2: Setting of the stylized case. Arcs (1) and (2) depict flows of goods, and arcs (3) and (4) depict financial flows.

Currency region $\mathrm{C} 1$ (domestic)

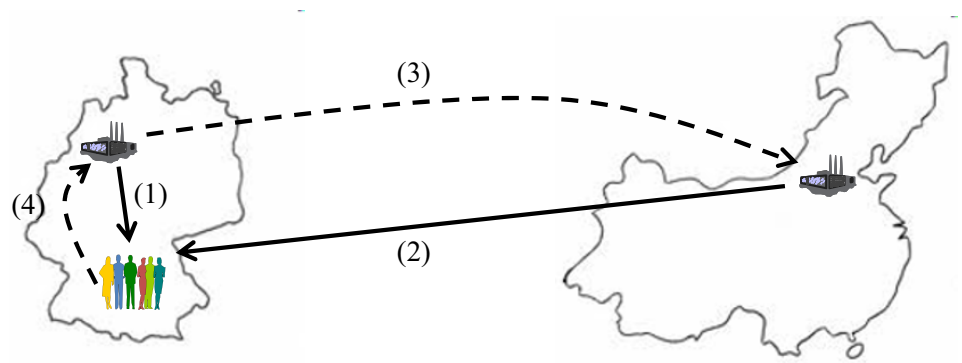

Table 4: Sales prices per unit in the domestic customer market.

\begin{tabular}{|c|c|c|c|}
\hline & P1 & P2 & P3 \\
\hline domestic market* & 20.0 & 35.0 & 70.0 \\
\hline
\end{tabular}

per unit are relatively high. However, we do not explicitly consider expenses for research, product development and other overhead expenses, which have to be deducted from the resulting profits. As indicated previously, capacity can be installed in ten discrete steps of 30,000 units per time period for product $\mathrm{P} 1,25,000$ units per time period for product P2 and 20,000 units per time period for product $\mathrm{P}_{3}$ at both of the plants. In the following section, we refer to the discrete capacity steps as production lines. For the installation of one production line, investment expenses of 250 million currency units at the beginning of the planning horizon and fixed operating expenses of 50 million currency units per time period are incurred. In the following section, we presume a weighted average cost of capital irwace of $8 \%$ and a maximal contract duration of 1 time period for both types of financial hedging instruments.

\subsection{The impact of exchange-rate and demand volatility}

Figure 3 shows efficient frontiers with respect to risk (CVaR 95\%) and expected profit for six different levels of exchange rates and demand volatilities $\sigma^{E, D}$ (see Appendix B for further details). In each of the six diagrams, four model variants are compared, namely, one version without financial instruments, one version with one type of financial contract (forwards or options) and one version with both types of financial contracts. The efficient frontiers were constructed using the objective function and the procedure described in section 3.4.2.

Figures 4 and 5 illustrate the corresponding distribution of capacities between the domestic and the foreign plant for the two model variants with and without financial hedging and six different levels of exchange rates and demand volatilities. Each of the twelve diagrams shows the number of production lines installed at the domestic and foreign plants for different levels of risk aversion $\lambda$.

Diagram 3(a) depicts the case of pure exchangerate uncertainty. For the solution yielding the maximal expected net present value $(\mathrm{ENPV}=37.2 \mathrm{bn}$. currency units) the abandonment of financial instruments results in significant risks (CVaR95 = $2.0 \mathrm{bn} . \mathrm{CU})$. As illustrated in the corresponding capacity diagram 4(a), this risk can be mitigated by shifting production lines from the foreign region to the domestic currency region and sacrificing expected profits due to higher expenses for production. However, using forward contracts in this situation, the efficient frontier reduces to just one point at the upper-right corner, which indicates that currency risk can be completely hedged by the use of forward contracts in the absence of demand uncertainty. Consequently, a shift in capacity toward the domestic currency region is unnecessary, as illustrated in diagram 4(b). Conversely, the results also confirm that option contracts are less efficient if only exchange-rate risk is present. This result can be explained by the risk pattern produced by option contracts. In particular, the owner has the choice to exercise the option or allow it to expire unused. Consequently, the thread of walking away with a loss incurred through the sunk costs of the option premium paid 
exists when profiting from upside potentials. In this context, another result can be deduced from diagram 3(a). Operational and financial hedging strategies are substitutes. Without options, the agent would simply relocate production to the domestic currency region. However, operational hedging becomes cheaper with the use of financial options because the option can mitigate some, but not all, of the exchange-rate risk. Consequently, the use of financial options yields a pareto front that is similar to the unhedged scenario but for better CVaR and ENPV combinations. Furthermore, due to the unbiasedness of financial markets, all of the results confirm the well-known fact that financial hedging cannot solely increase expected profits. As mentioned previously, financial hedging and operational hedging strategies are substitutes. Consequently, if the financial instruments are not capable of sufficiently reducing the risk, the agent can use operational hedging to further minimize risk. Compared with the unhedged scenario, operational hedging becomes cheaper which can raise profits (e.g., 3(a)). If both financial instruments can be employed, the model generates the same solution as the forwards-only model, which is also valid for the cases of increased demand uncertainty. In this setting, financial instruments are no longer capable of completely eliminating risk (see Figures 3(b) to $3(\mathrm{~d})$ ) and the volatility of the NPV increases. The maximal ENPV decreases only marginally from $37.2 \mathrm{bn}$. CU to $36.0 \mathrm{bn}$. CU, whereas the best achievable CVaR95 using forward contracts decreases from approximately $37 \mathrm{bn}$. CU to approximately 17 bill. CU.

Although the model variant without financial instruments tends to install fewer production lines in the domestic currency region (Figures 4(c), 4(e) and 5(e)), the model variant with incorporated financial instruments increases the number of domestic production lines (Figures 4(d), 5(f) and $5(\mathrm{f})$ ). With higher demand volatility, the models install a smaller total number of production lines in the cases of high risk aversion ( $\lambda$-value near 1.0) and accept lost sales. The maximal ENPV decreases further with a decreasing exchangerate volatility from $36.0 \mathrm{bn}$. CU for the case $\sigma^{E}=0.45, \sigma^{D}=0.25$ to $34.6 \mathrm{bn}$. CU for the case $\sigma^{E}=0, \sigma^{D}=0.25$, which seems to be counterintuitive (Figures 3 (d) to $3(\mathrm{f})$ ). The corresponding capacity diagrams 5 (a) to 5 (d) show that fewer domestic production lines are installed with decreas- ing exchange-rate volatility. Capacity decisions are less influenced by the use of financial hedging instruments. Diagram 3(f) clearly shows that it is not possible to use financial hedging instruments to hedge against demand uncertainty.

It is assumed that in the case of joint demand and exchange-rate uncertainty, financial instruments should be capable of completely hedging the fraction of risk that is induced by exchangerate volatility. If this notion was valid, the models 5 (a) and 5(f) should yield similar capacity decisions. However, the two capacity diagrams differ significantly: a significantly higher number of production lines is installed in the domestic currency region for the case of high exchange-rate volatility despite the use of financial hedging. This result indicates that exchange-rate uncertainty cannot be completely eliminated by financial hedging in the presence of demand uncertainty in our stylized case. Section 4.6 provides a comprehensive discussion of consequences for the strategic planning of production networks and alternative planning approaches.

\subsection{The impact of investment expenses}

To investigate the impact of the level of investment expenses, we conducted the analysis from section 4.3 for two additional variants of our model instance, in which we lower the levels of investment expenses and fixed operating expenses to $50 \%$ and $25 \%$, respectively. These changes are implemented in our model by multiplying investment expenses $c_{c}^{\text {linebuild }}$ and fixed operating expenses $c_{c}^{\text {lineoperate }}$ by a constant $\alpha$ with $0 \leq \alpha \leq 1$. The results in terms of the efficient risk/profit frontiers are displayed in Figure 6. A distinct decrease in fixed expenses causes an increase in expected profits and lower risk. However, there is an additional interesting effect, which can be identified in diagram 6(a) and subsequent diagrams. Diagram 6(a) illustrates how the efficient frontiers extend to the left (increasing potential loss of expected profit) and shift to the bottom (decreasing CVaR) with increasing volatility. However, for the highest volatility of $\sigma=0.45$ this intuitive behavior stops and the associated efficient frontier is shifted to the upper-right corner. For pure expected profit maximization a significant increase in expected profit is evident. Thus, in this case we observe an increase in expected profits and a 
Figure 3: Impact of exchange-rate volatility and financial hedging on risk/profit efficient frontiers. Generated with coinciding interest rates $i r_{C 1}=4 \%$ and $i r_{C 2}=4 \%$ in the domestic and the foreign currency region, respectively.

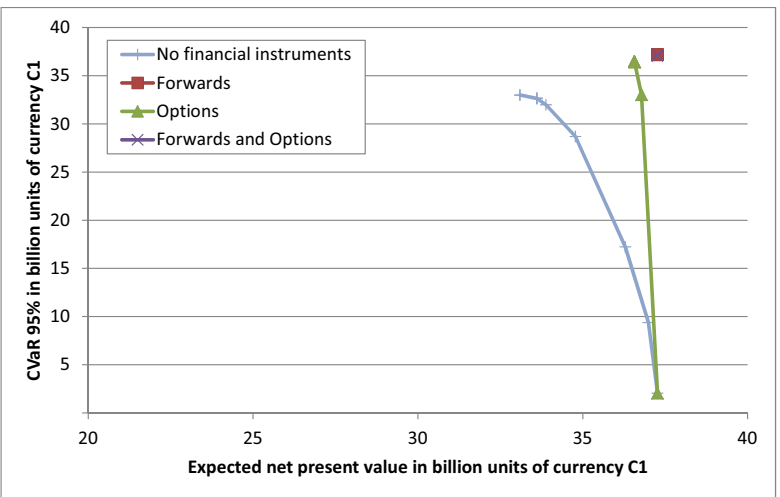

(a) $\sigma^{E}=0.45, \sigma^{D}=0$

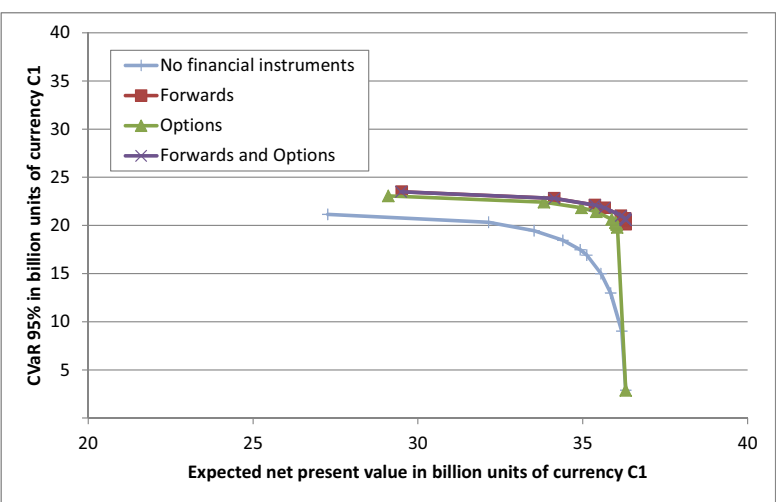

(c) $\sigma^{E}=0.45, \sigma^{D}=0.15$

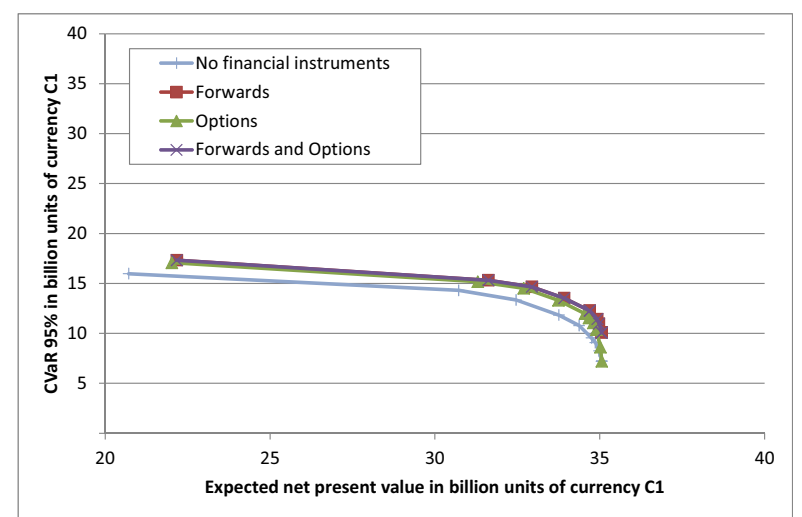

(e) $\sigma^{E}=0.25, \sigma^{D}=0.25$

decreased risk (increasing CVaR) for an increase in exchange-rate volatility. This effect, which is counter-intuitive, is retained for the model with financial hedging (cf. diagram 6(b)) and is amplified for lower fixed expenses (cf. diagrams 6(c) to 6(f)). Figure 7 shows that lower fixed expenses and higher exchange-rate volatility produce a sig-

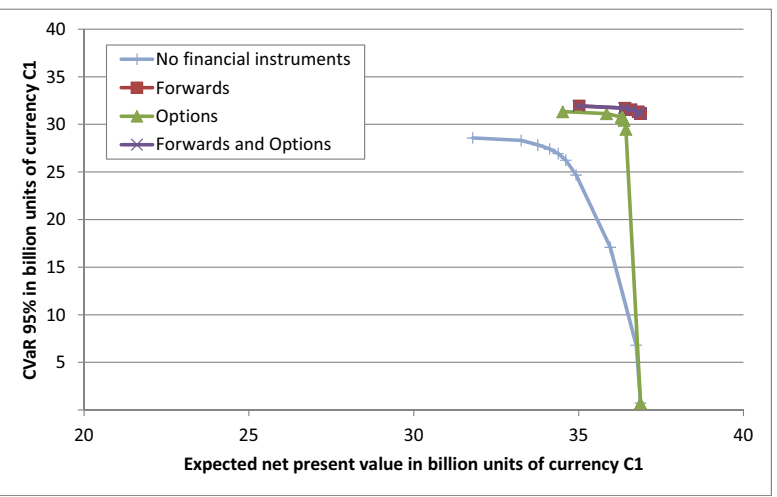

(b) $\sigma^{E}=0.45, \sigma^{D}=0.05$

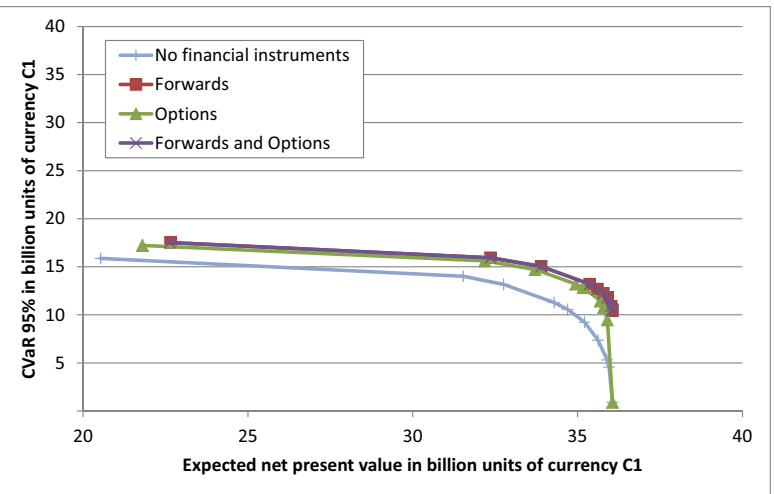

(d) $\sigma^{E}=0.45, \sigma^{D}=0.25$

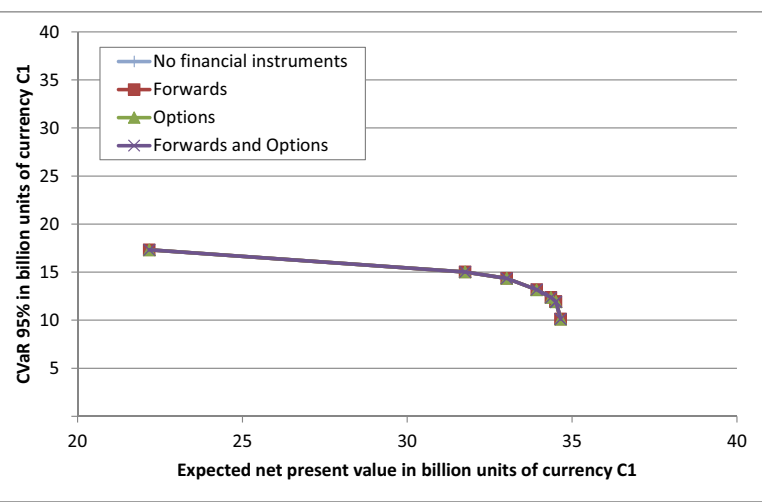

(f) $\sigma^{E}=0, \sigma^{D}=0.25$

nificantly higher number of production lines in the domestic and foreign currency regions. Thereby, the model gains more flexibility regarding the use of operational hedging and the impact of financial hedging instruments on capacity decisions, ENPV and decreased risk. 
Figure 4: Impact of demand volatility and financial hedging on capacity installation under exchange-rate and demand uncertainty. Generated with coinciding interest rates $i r_{C 1}=4 \%$ and $i r_{C 1}=4 \%$ in the domestic currency region and the foreign currency region, respectively.

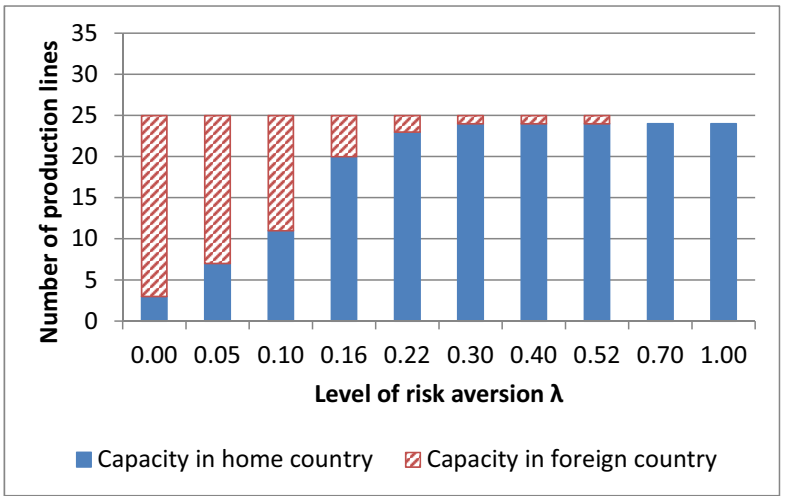

(a) No financial instruments, $\sigma^{E}=0.45, \sigma^{D}=0$

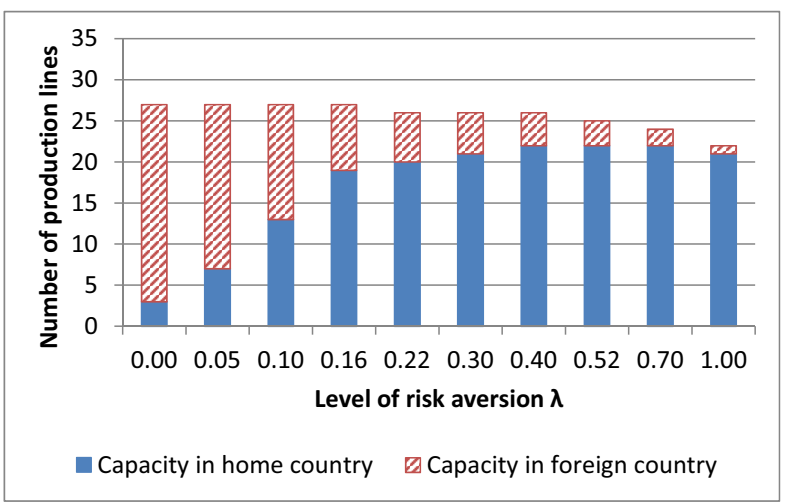

(c) No financial instruments, $\sigma^{E}=0.45, \sigma^{D}=0.05$

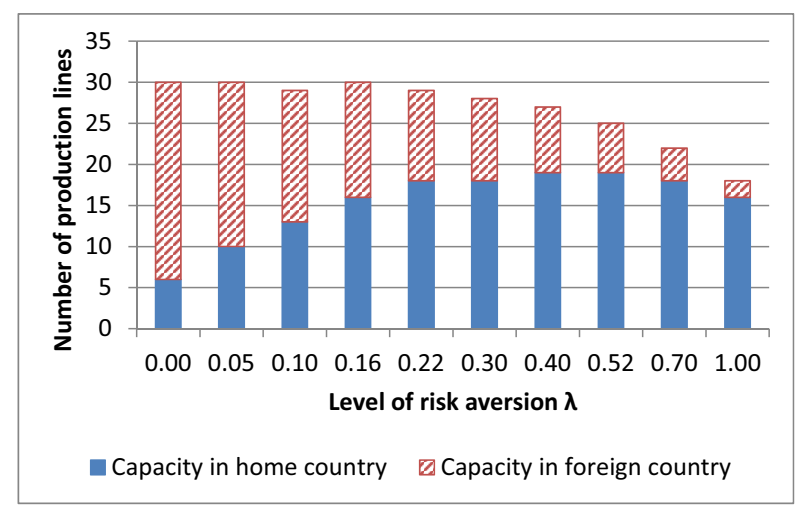

(e) No financial instruments, $\sigma^{E}=0.45, \sigma^{D}=0.15$

\subsection{The impact of interest rate spreads}

Whereas we presumed coinciding levels of interest rates of $4 \%$ in the preceding investigations, we will now analyze the impact of interest rate spreads. To this end, we generated further results with interest rates of $1 \%$ and $7 \%$ in the foreign currency region.

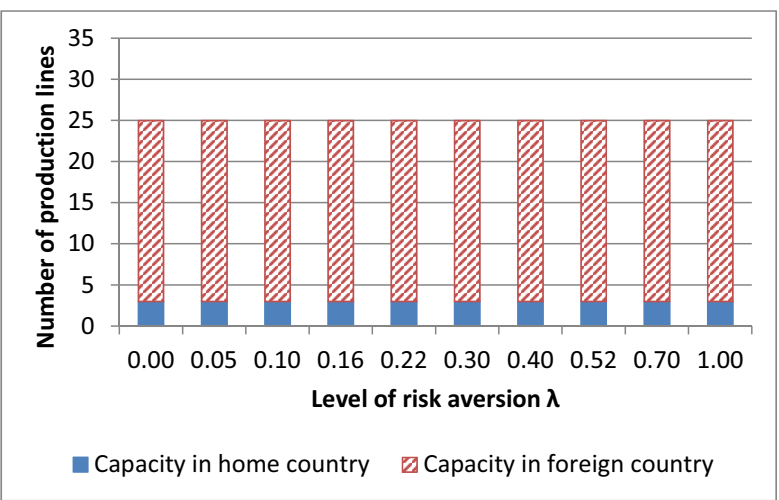

(b) With forwards and options, $\sigma^{E}=0.45, \sigma^{D}=0$

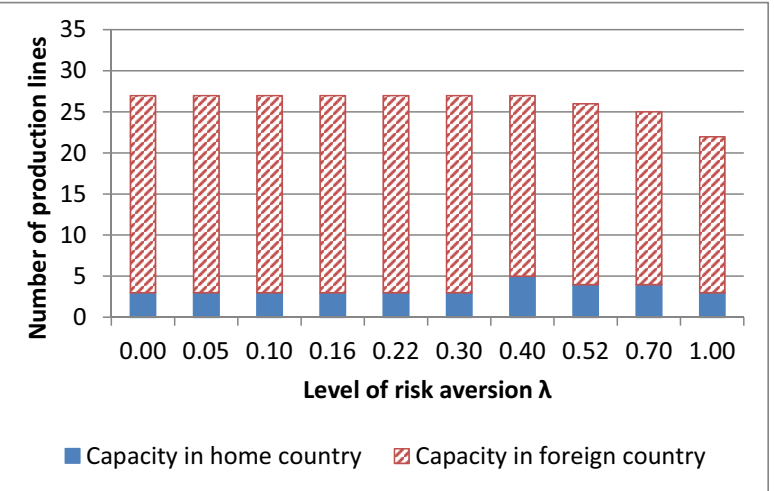

(d) With forwards and options, $\sigma^{E}=0.45, \sigma^{D}=0.05$

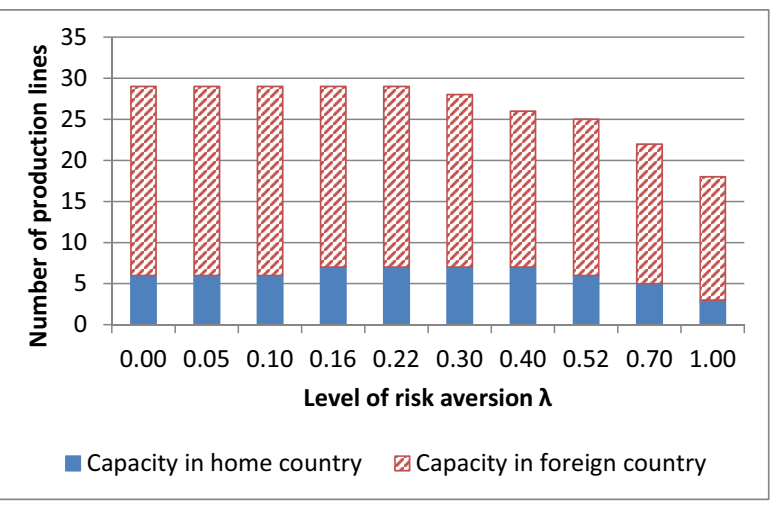

(f) With forwards and options, $\sigma^{E}=0.45, \sigma^{D}=0.15$

Note that in the following discussion of results, $i r_{C 1}$ corresponds to $i^{r e f}$. Following the same regime considered above, the results are summarized in Figure 8 in terms of efficient risk/profit frontiers and in Figure 9 in terms of capacity distributions. Interest rates affect the model in two ways: First, 
Figure 5: Impact of exchange-rate volatility and financial hedging on capacity installation und exchange rate and demand uncertainty. Generated with coinciding interest rates $i r_{C 1}=4 \%$ and $i r_{C 1}=4 \%$ in the domestic currency region and the foreign currency region, respectively.

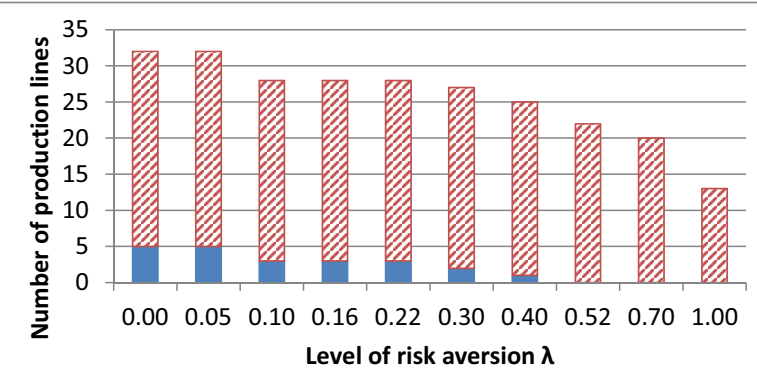

Capacity in home country Capacity in foreign country

(a) No financial instruments, $\sigma^{E}=0, \sigma^{D}=0.25$

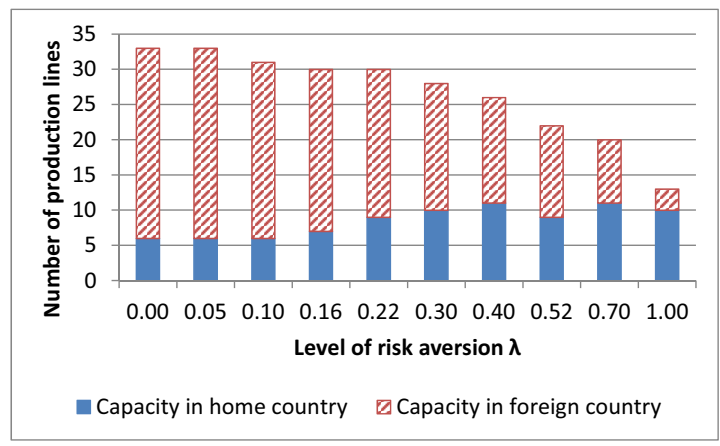

(c) No financial instruments, $\sigma^{E}=0.25, \sigma^{D}=0.25$

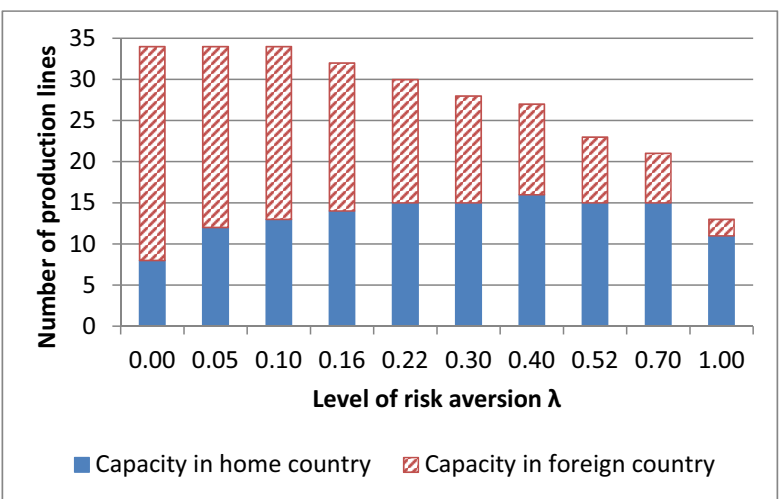

(e) No financial instruments, $\sigma^{E}=0.45, \sigma^{D}=0.25$

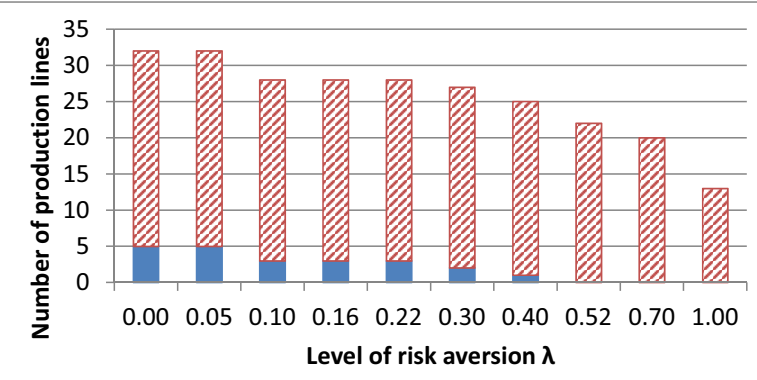

Capacity in home country $\square$ Capacity in foreign country

(b) With forwards and options, $\sigma^{E}=0, \sigma^{D}=0.25$

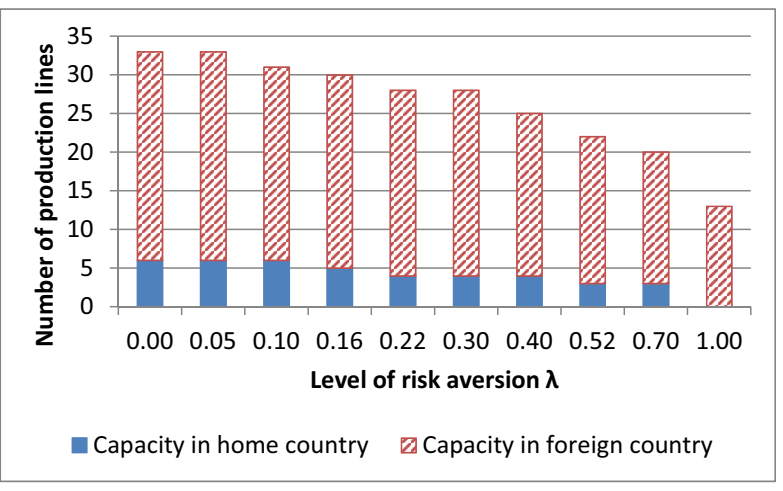

(d) With forwards and options, $\sigma^{E}=0.25, \sigma^{D}=0.25$

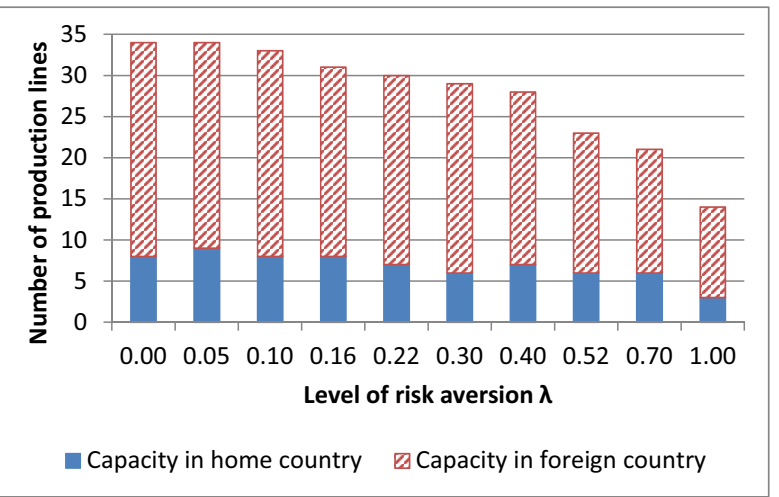

(f) With forwards and options, $\sigma^{E}=0.45, \sigma^{D}=0.25$

terpreted as a bias toward an appreciation of the foreign currency and a devaluation of the domestic currency, which in turn leads to an increased impact of exchange-rate volatility on production expenses at the foreign plant. The consequences are lower expected profits and a fortified relocation of production lines toward the domestic currency 
Figure 6: Impact of investment expenses on risk/profit efficient frontiers (with $\sigma^{D}=0.25$ ).

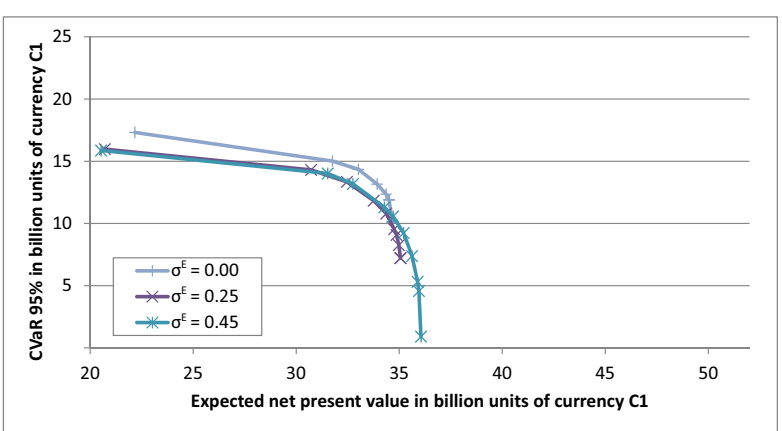

(a) No financial instruments, $\alpha=1.0$

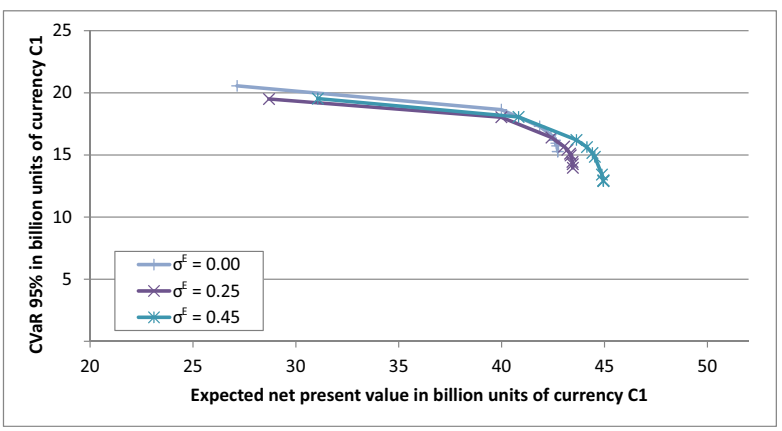

(c) No financial instruments, $\alpha=0.5$

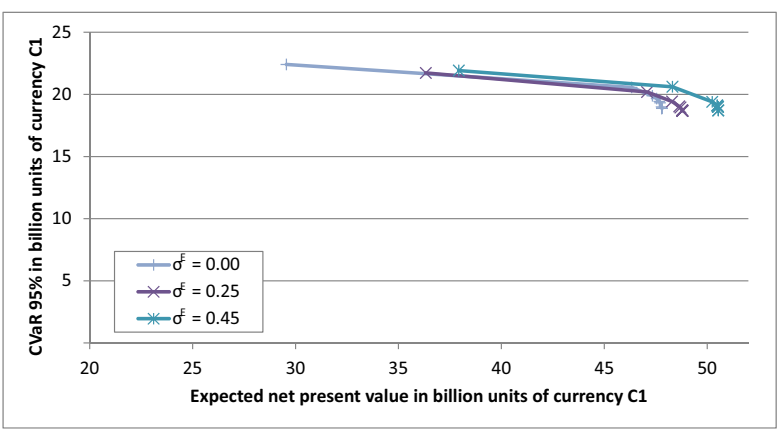

(e) No financial instruments, $\alpha=0.25$

region.

These effects can be clearly observed in diagrams 8(c), 9(e) and 9(f). Inevitably, the described effects are inversed if the domestic interest rate is smaller than the foreign interest rate. This case can be studied by considering the diagrams 8(a), 9(a) and 9(b). Moreover, the results reveal that the use of financial instruments contributes more effectively to risk mitigation if the foreign currency depreciates.

Second, interest rates directly influence the forward rate of forward contracts according to formula (14) and the prices of option contracts according to formulas (19) and (20). Due to Interest

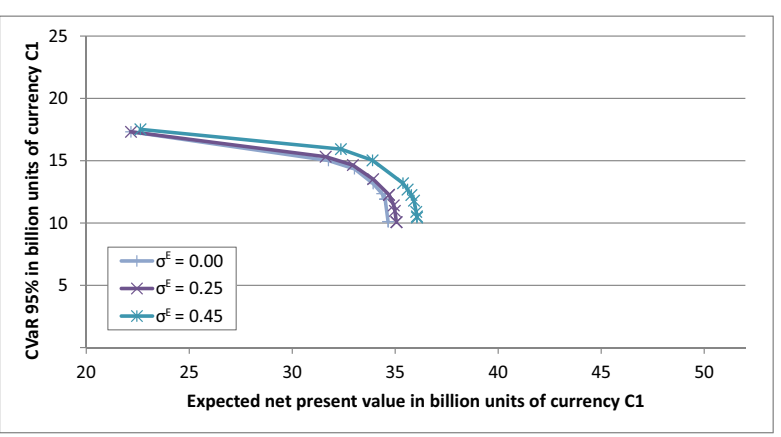

(b) With forwards and options, $\alpha=1.0$

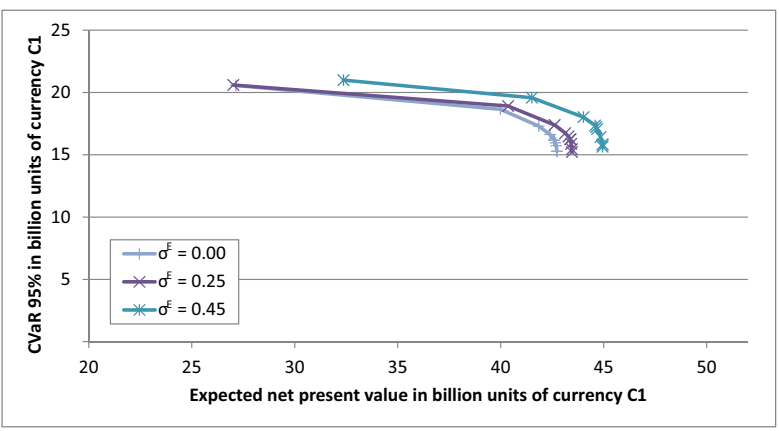

(d) With forwards and options, $\alpha=0.5$

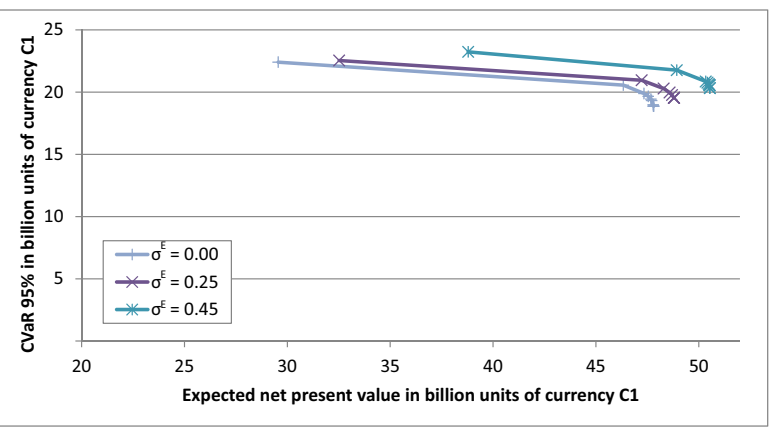

(f) With forwards and options, $\alpha=0.25$

Rate Parity, the hedged exchange rate is subject to interest changes. Forward contracts, however, cost nothing to enter, which means that the use of forward contracts is equally appealing. On the other hand, option contracts can become more or less expensive because the interest rate spread, i.e., the difference $i r^{r e f}-i r_{c}$, impacts the strike price of the option. More precisely, when pricing the option we have assumed that the strike price equals the forward rate which is in turn based on the theory of Interest Rate Parity. Consequently, interest changes in either currency will change the forward rates and strike prices, respectively. Hence, a positive interest spread, i.e., $i r^{r e f}>i r_{c}$ increases 
Figure 7: Impact of the level of investment expenses and fixed expenses $\alpha$ on capacity installation (with $\sigma^{D}=0.25$ ).

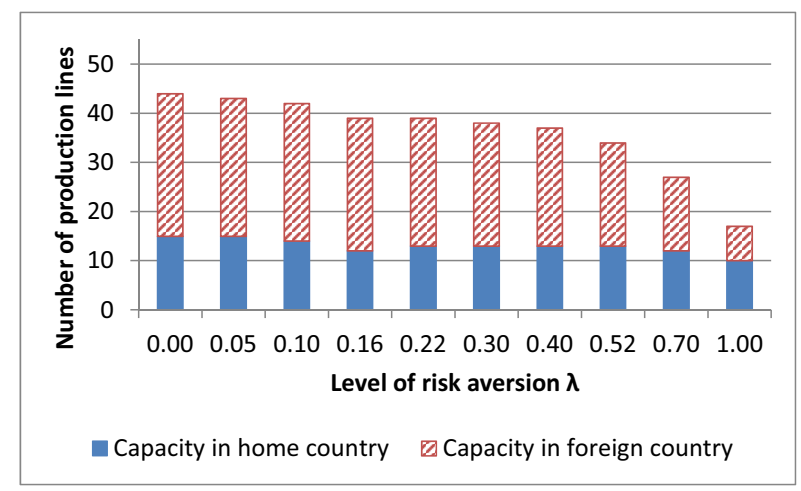

(a) No financial instruments, $\sigma^{E}=0.25, \alpha=0.5$

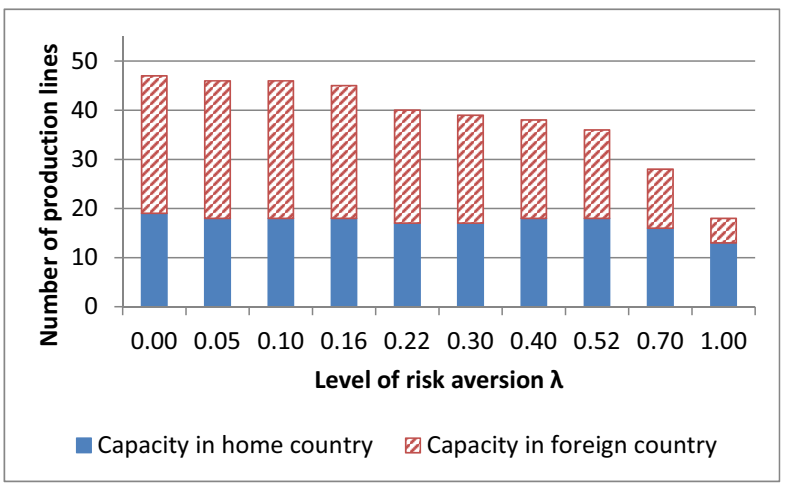

(c) No financial instruments, $\sigma^{E}=0.45, \alpha=0.5$

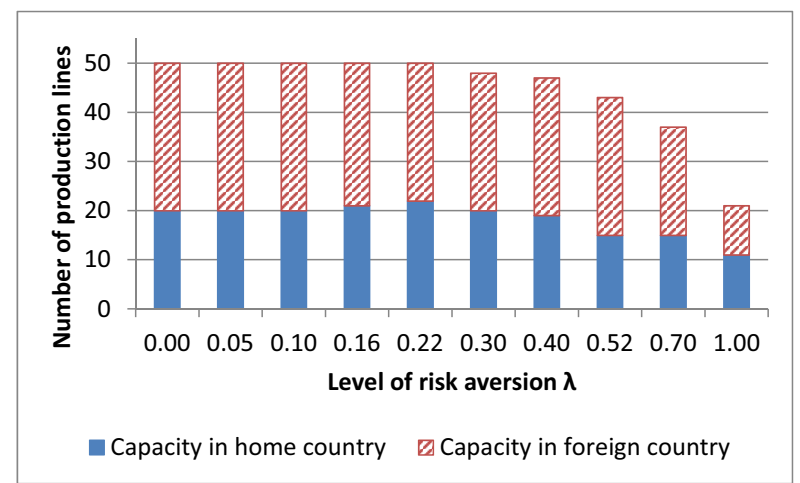

(e) No financial instruments, $\sigma^{E}=0.25, \alpha=0.25$

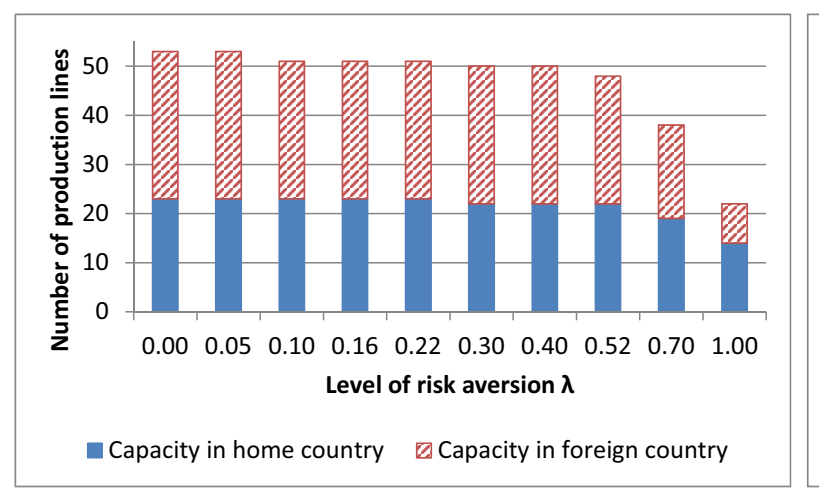

(g) No financial instruments, $\sigma^{E}=0.45, \alpha=0.25$

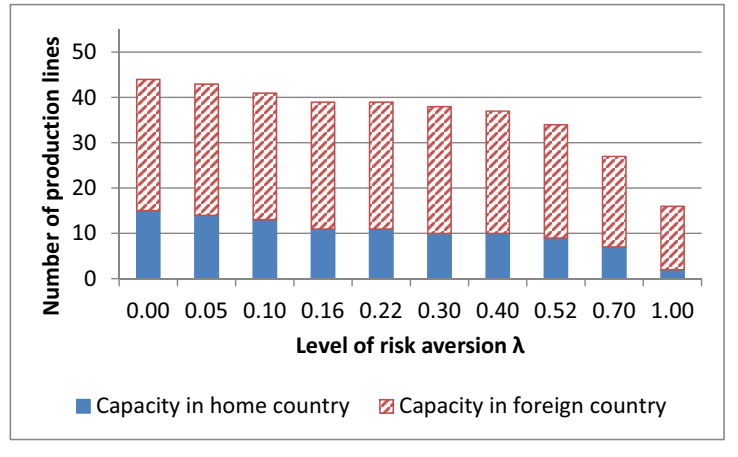

(b) With forwards and options, $\sigma^{E}=0.25, \alpha=0.5$

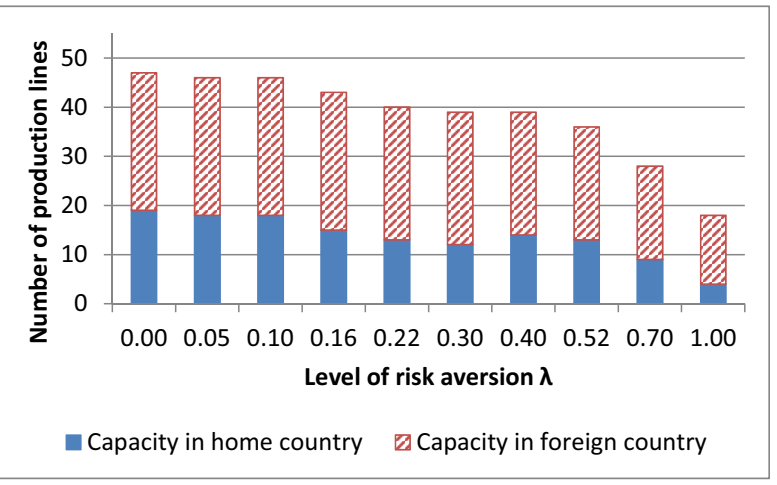

(d) With forwards and options, $\sigma^{E}=0.45, \alpha=0.5$

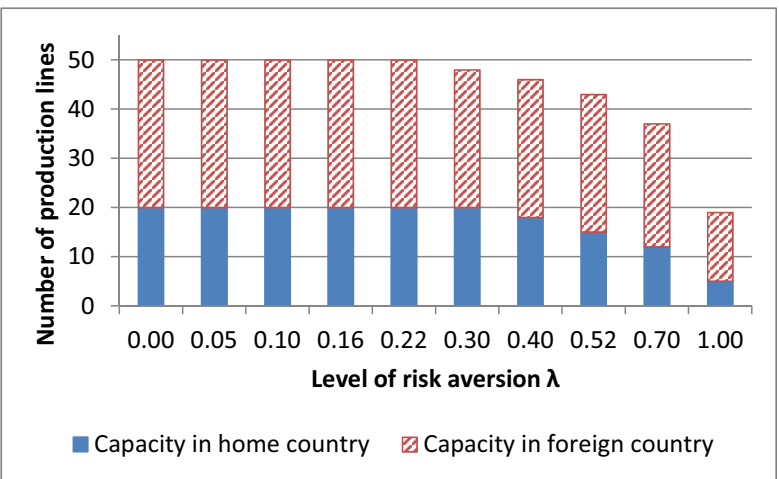

(f) With forwards and options, $\sigma^{E}=0.25, \alpha=0.25$

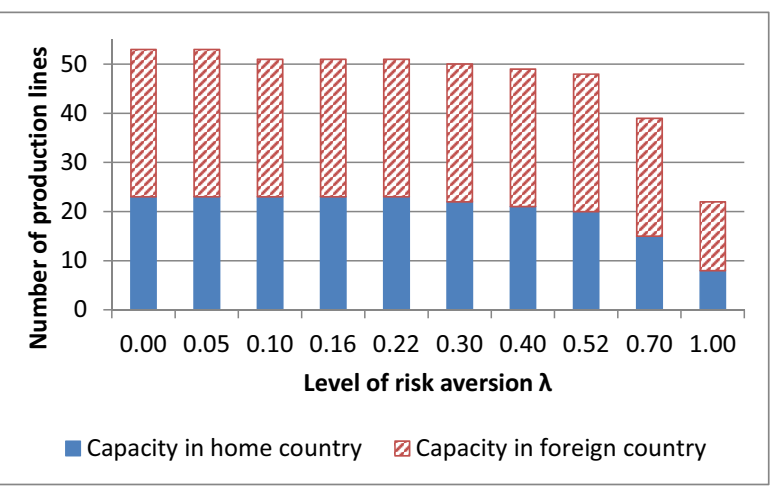


Figure 8: Impact of interest rate spreads on risk/profit efficient frontiers.

Generated with $\sigma^{E}=0.45$ and $\sigma^{D}=0.25$.

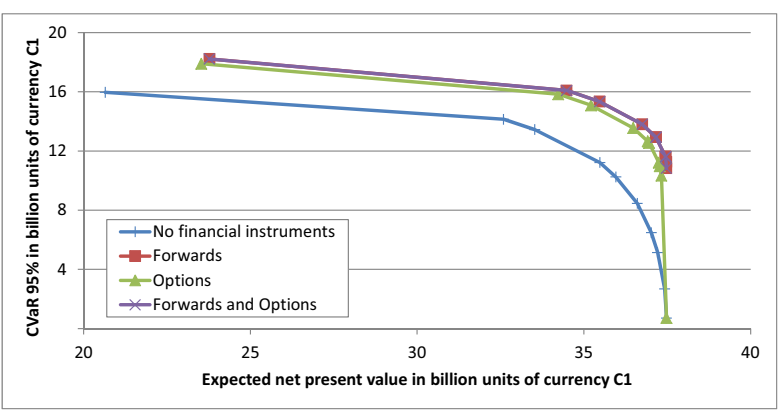

(a) $i r_{C 1}=4 \%, i r_{C 2}=7 \%$

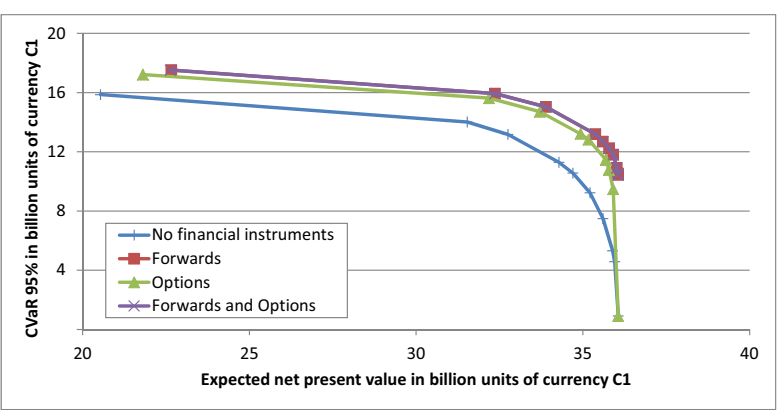

(b) $i r_{C 1}=4 \%, i r_{C 2}=4 \%$

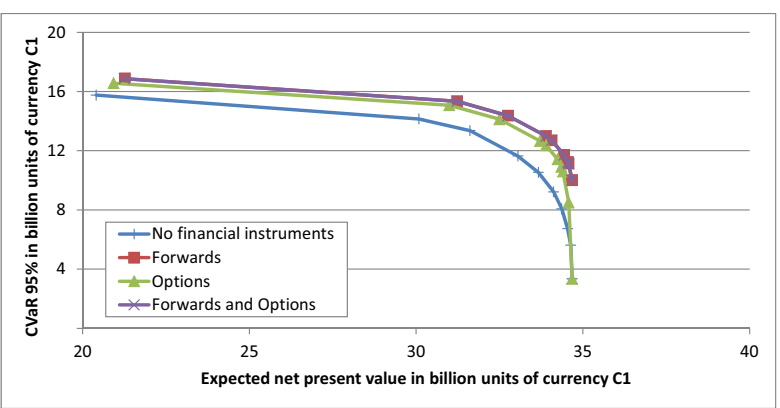

(c) $i r_{C 1}=4 \%, i r_{C 2}=1 \%$

the strike price of the option. Ceteris paribus, the option becomes less expensive because the option is presently out-of-the-money. If, however, $i r^{r e f}<i r_{c}$, the option is currently far in-the-money and possesses an intrinsic value that the option premium must cover. Hence, hedging against exchange risk becomes more expensive. Though both effects tend to impact the optimal choice of financial instruments and the number of production lines, we observe that the first effect, i.e., the direct impact of appreciation or depreciation of a currency tends to dominate.

\subsection{Discussion of alternative planning approaches}

From the viewpoint of a decision maker, there are now several approaches for handling exchangerate uncertainty:

- Deterministic approach: This approach completely neglects exchange-rate uncertainty and plans under given exchange rates. One argument in favor of this approach that can be found in the literature is that exchange-rate risk can be mitigated completely by the use of financial instruments, which is confirmed by our analysis for the case of absent demand uncertainty. However, under uncertain product demand, planning solutions of the model variant with zero exchange-rate volatility (Figure 5(a)) and solutions of the model variant with exchange rate uncertainty and integrated financial hedging (Figure $5(\mathrm{f})$ ) differ considerably, as discussed in section 4.3. Therefore, given a significant level of demand volatility, neglecting exchange-rate uncertainty does not seem to be a reasonable option for the decision maker.

- Stochastic approach, no financial instruments: This approach models exchange-rate (and demand) uncertainty explicitly but does not consider financial hedging. In our illustrative case, this approach overestimates the impact of exchange-rate fluctuations and tends to relocate production lines to the domestic plant too early with increasing risk aversion. It therefore does not fully exploit cost advantages for a given level of risk aversion.

- Sequential approach: An alternative approach is to construct and evaluate possible solutions in two subsequent steps. The first step consists in solving the stochastic model under demand and exchange-rate uncertainty without financial instruments. Second, an optimal financial hedging strategy is derived by an adequate procedure based on the optimal investment and production decisions from the first step. We implemented this approach by fixing the optimal solution values of the stochastic model without financial hedging in the integrated model. The solutions of this approach are depicted as single points in Figure 10. It 
Figure 9: Impact of interest rate spreads on capacity installation. Generated with $\sigma^{E}=0.45$ and $\sigma^{D}=0.25$.

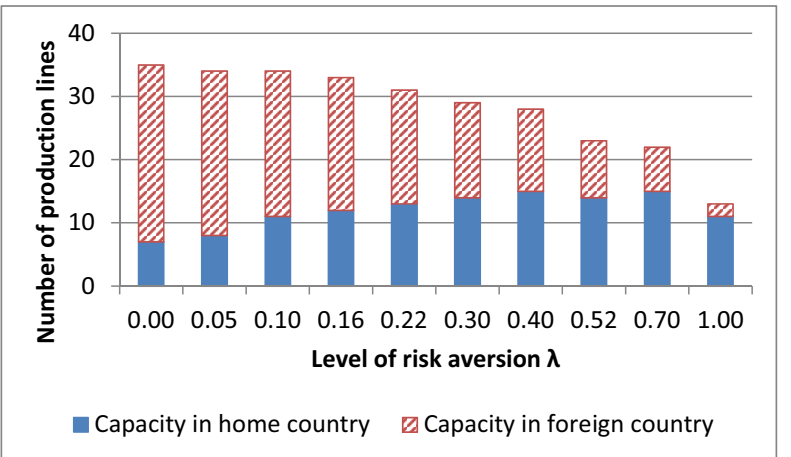

(a) $i r_{C 1}=4 \%, i r_{C 2}=7 \%$, no financial instruments

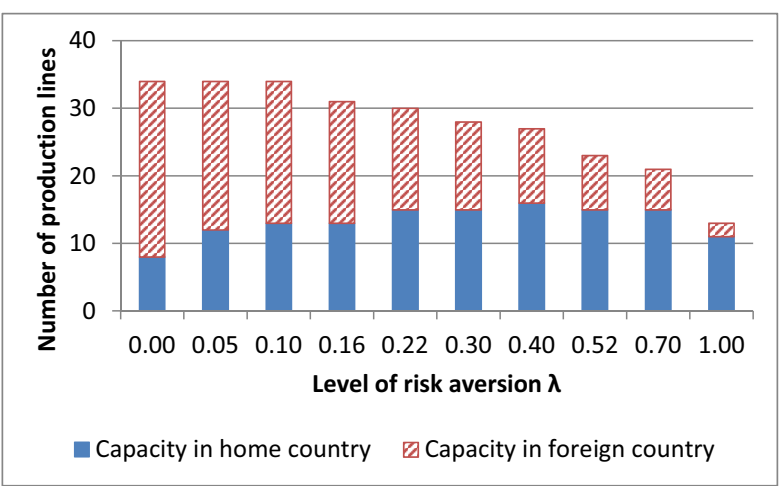

(c) $i r_{C 1}=4 \%, i r_{C 2}=4 \%$, no financial instruments

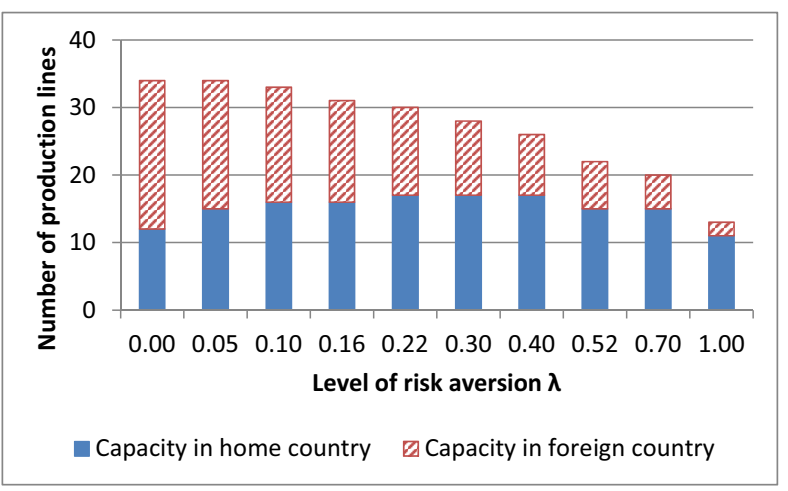

(e) $i r_{C 1}=4 \%, i r_{C 2}=1 \%$, no financial instruments

can be observed that the solutions of the model without financial instruments are shifted directly upward by evaluating them under an optimal financial hedging strategy. It is clear that these solutions are not guaranteed to form an efficient frontier. However, in all cases, this approach is able to generate the maximal ENPV solution and to produce a correct risk assessment by complementing it with the optimal financial hedging strategy. If no demand un-

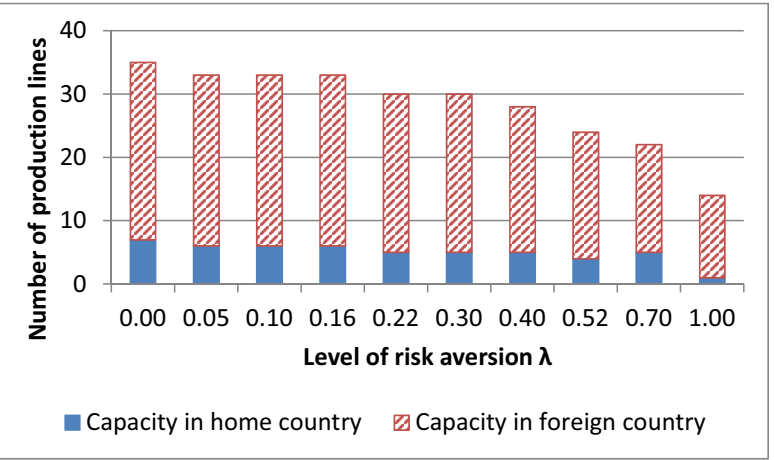

(b) $i r_{C 1}=4 \%, i r_{C 2}=7 \%$, with forwards and options

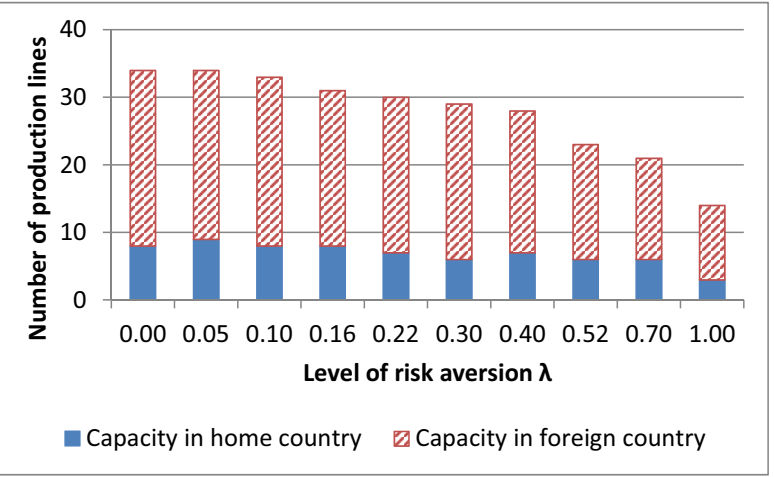

(d) $i r_{C 1}=4 \%, i r_{C 2}=4 \%$, with forwards and options

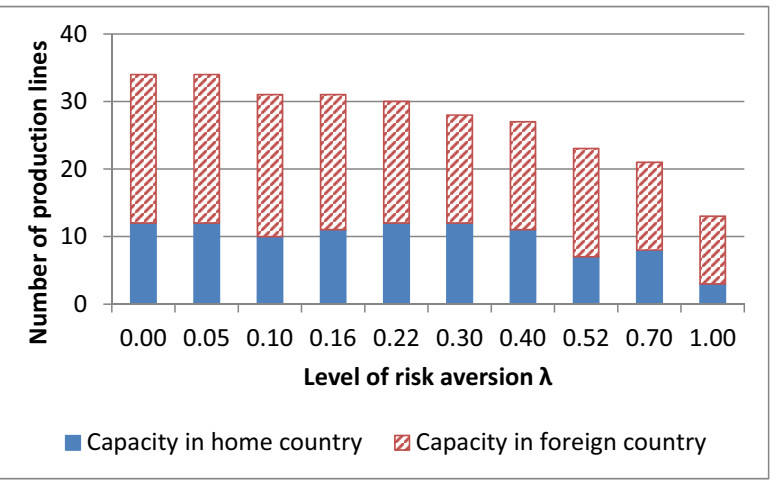

(f) $i r_{C 1}=4 \%, i r_{C 2}=1 \%$, with forwards and options

certainty is present (Figure 10(a)), this point coincides with the complete efficient frontier of the integrated model, indicating that separation holds, i.e., production and hedging decision can be performed separately and delegation to an individual other than the financial manager is possible. For increasing demand uncertainty, however, the sequential approach is not able to generate an acceptable approximation of the efficient frontier of the integrated 
model. In particular, in the case of the highest demand volatility (Figure 10(a)), a significant gap remains, which would lead to a systematic overestimation of currency risk associated with the relocation of production lines toward the domestic currency region. An implication of this result is that separation of the firm's financial and production decisions is no longer advisable.

- Integrated stochastic approach: This approach, which we propose herein, considers exchange-rate and demand uncertainty and financial hedging instruments explicitly within one integrated model. Consequently, the approach considers that under demand and exchange-rate uncertainty the production decisions can no longer be delegated to an individual, which optimizes production. Rather, both decisions must be made simultaneously by one agent. In addition, possible investment decisions are evaluated most realistically in terms of expected profit and risk by determining the optimal combination of operational and financial hedging instruments. The integrated model is able to consider the impact of varying exchange-rate and demand volatilities, different levels of investment expenses, fixed expenses and interest rate spreads on capacity location and dimensioning, which is not possible using the previously discussed planning approaches.

A general criticism of stochastic models concerns the assumption that distributions of random parameters are assumed to be known. Furthermore, one can argue that in a case study in which a stochastic model and the data are based on the same stochastic process, the comparison with a deterministic model always favors the stochastic model. However, in our view, neither statement reduces the benefit of a stochastic model for the decision maker, which consists of the opportunity to explicitly model uncertainty by means of a scenario tree. The stochastic model is then able to generate a solution that actively hedges against uncertainty. This is not possible with a deterministic model. Certainly, assumptions must be made concerning the model of uncertainty. However, much stronger assumptions must be made when generating the data for a deterministic model (e.g., through aggregation).

Therefore, in our view, the decision maker should deploy the integrated model to find the investment decision that reflects best his or her level of risk aversion and considers the various effects that can occur under uncertain demands and exchange rates as demonstrated in this study, with the greatest possible accuracy.

\section{Conclusion}

Two of the main risks global manufacturers are facing today are induced by uncertain exchange rates and product demands. Exchange-rate risk is predominantly hedged by means of financial derivatives. Traditionally, strategic production network planning and financial hedging is treated separately, both in the firm's organizations as well as in the research literature, which is the main cause of classical two-period-hedging results indicating that a separation theorem holds, i.e. production and hedging decision can be performed separately, and delegation to an individual other than the financial manager is possible. In reality, however, production decisions take place at different points in time, putting stress on a multi-period decision framework, and are subject to a greater variety of risks. In this study, we presented a multi-stage stochastic programming model for the integrated planning of strategic production network design and financial hedging under uncertain exchange rates. The analysis of our illustrative case indicates that the integrated model can result in better strategic planning decisions in terms of expected profit and conditional value at risk compared to the traditional, non-integrated approach. This result is due to the observation, that separation no longer holds for our small-scale example under combined exchange-rate and demand uncertainty. Accordingly, the production decisions can no longer be delegated to an agent who optimizes production individually. Rather, both decisions must be made simultaneously by one agent.

The presented model may constitute a starting point for further research. To solve the model for more realistic cases, a more sophisticated solution framework must be developed, deploying decomposition methods for the multi-stage stochastic programming model and scenario aggregation techniques to manage more time periods and more 
Figure 10: Comparison of risk/profit efficient frontiers w.r.t. different planning approaches.

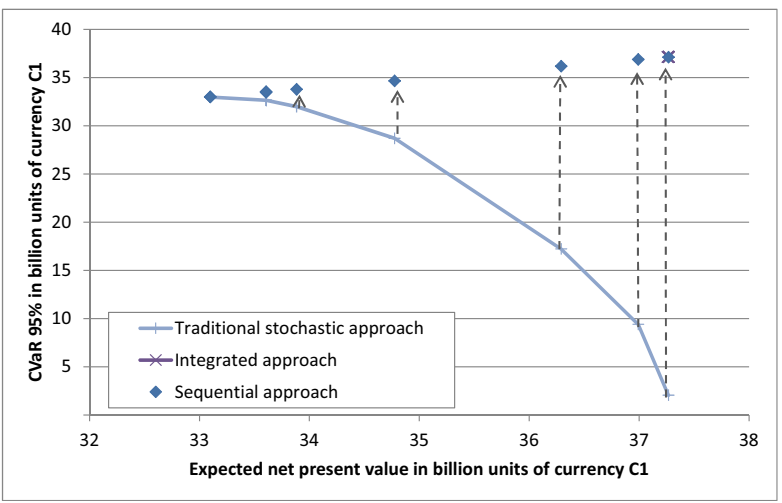

(a) $\sigma^{E}=0.45, \sigma^{D}=0$

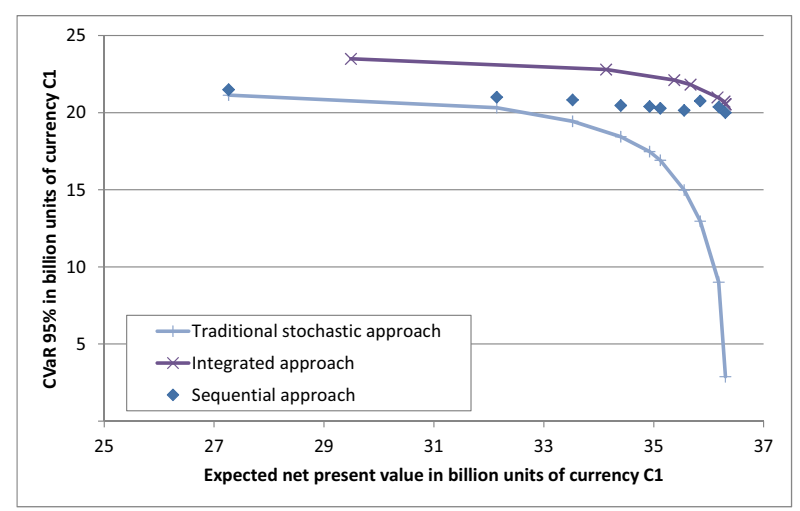

(c) $\sigma^{E}=0.45, \sigma^{D}=0.15$

than two currency regions. The financial part of the model should be extended to consider imperfect financial markets, including e.g., transaction costs or liquidity risk.

\section{Appendix A: Non-anticipativity}

Above we present the model formulation of the deterministic equivalent in implicit form. In this form, all of the decision variables associated with a stage of the scenario tree are indexed over all scenarios (leaves of the scenario tree). The following non-anticipativity constraints identify all of the variables associated with a certain node of the tree. For a node $i$ in the tree, the scenario indices of the variables to be identified can be determined by the subset of leaf nodes for each of which node $i$ is on the path from the leaf node to the root node. Note that we assume that no production is possible in the first time period that is associated with the root node of the scenario tree. We present the

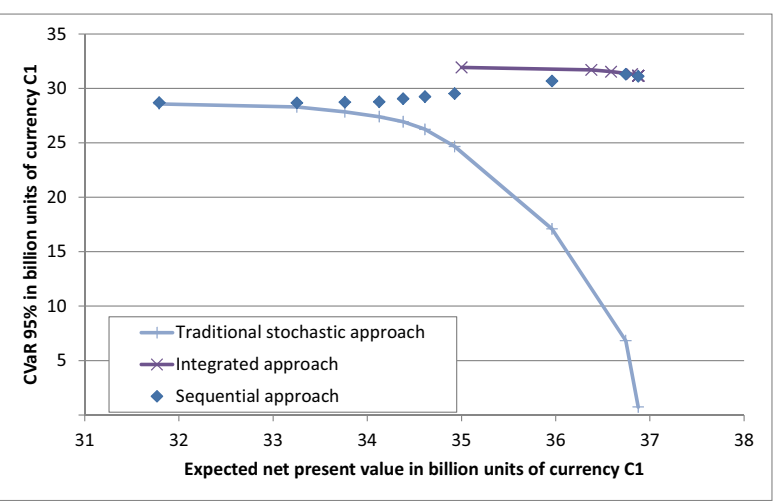

(b) $\sigma^{E}=0.45, \sigma^{D}=0.05$

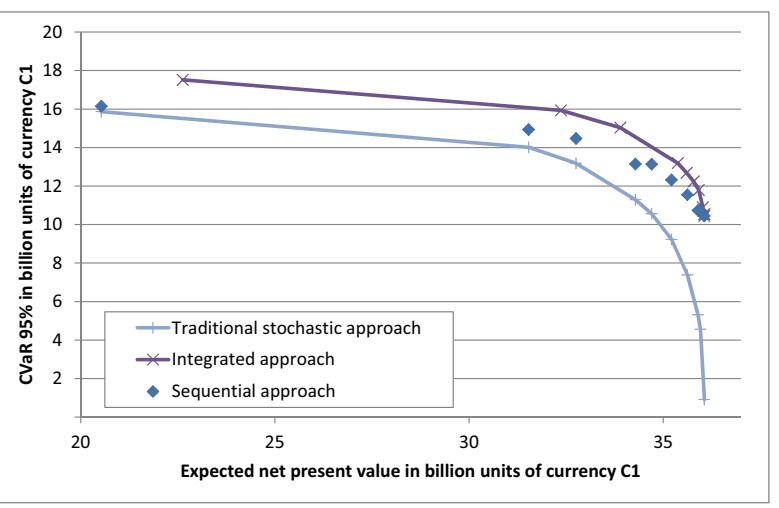

(d) $\sigma^{E}=0.45, \sigma^{D}=0.25$

non-anticipativity constraints that yield the scenario tree depicted in Figure 1 for the decision variables $x_{i j p t s}$ and call $_{\text {ctt's }}^{b}$. For the remaining variables, the non-anticipativity constraints follow the same scheme.

(36)

$$
x_{i, j, p, 1, s}=0 \quad \forall i, j, p, s
$$

(37)

$$
\begin{array}{r}
x_{i, j, p, 2,256^{*} k+s}=x_{i, j, p, 2,256^{*} k+s+1} \\
\forall i, j, p, s<256, k \in\{0 \ldots 3\}
\end{array}
$$

(38)

$$
\begin{aligned}
& x_{i, j, p, 3,64^{*} k+s}=x_{i, j, p, 3,64^{*} k+s+1} \\
& \forall i, j, p, s<64, k \in\{0 \ldots 15\}
\end{aligned}
$$

(39)

$$
\begin{aligned}
& x_{i, j, p, 4,16^{*} k+s}=x_{i, j, p, 4,16^{*} k+s+1} \\
& \forall i, j, p, s<16, k \in\{0 \ldots 63\}
\end{aligned}
$$

(40)

$$
\begin{aligned}
x_{i, j, p, 5,4^{*} k+s} & =x_{i, j, p, 5,4^{*} k+s+1} \\
\forall i, j, p, s & <4, k \in\{0 \ldots 255\}
\end{aligned}
$$


(41) call $_{c, 1, t^{\prime}, s}^{b}=$ call $_{c, 1, t^{\prime}, s+1}^{b}$ $\forall c, 1<t^{\prime} \leq 1+M H T, s<1024$

(42)

$$
\begin{aligned}
& \text { call }_{c, 2, t^{\prime}, 256^{*} k+s}^{b}=\operatorname{call}_{c, 2, t^{\prime}, 256^{*} k+s+1}^{b} \\
& \quad \forall c, 2<t^{\prime} \leq 2+M H T, s<256, k \in\{0 \ldots 3\}
\end{aligned}
$$

$$
\begin{aligned}
& \text { call }_{c, 3, t^{\prime}, 64^{*} k+s}^{b}=\text { call }_{c, 3, t^{\prime}, 64^{*} k+s+1}^{b} \\
& \forall c, 3<t^{\prime} \leq 3+M H T, s<64, k \in\{0 \ldots 15\}
\end{aligned}
$$

$$
\begin{aligned}
& \text { call }_{c, 4, t^{\prime}, 16^{*} k+s}^{b}=\text { call }_{c, 4, t^{\prime}, 16^{*} k+s+1}^{b} \\
& \forall c, 4<t^{\prime} \leq 4+M H T, s<16, k \in\{0 \ldots 63\}
\end{aligned}
$$

(45)

$$
\begin{aligned}
& \text { call }_{c, 5, t^{\prime}, 4^{*} k+s}^{b}=\text { call }_{c, 5, t^{\prime}, 4^{*} k+s+1}^{b} \\
& \quad \forall c, 5<t^{\prime} \leq 5+M H T, s<4, k \in\{0 \ldots 255\}
\end{aligned}
$$

\section{Appendix B: Parameters of the scenario trees in the illustrative example}

The values of $\sigma^{E, D}$ used in our analysis are associated with the following values for $u^{E, D}$ and $p^{u p}$ in accordance to equations (33) and (34), where $p^{u p}$ is multiplied by 0.5 to account for demand states: $\sigma^{E, D}=0: u^{E, D}=1, p^{u p}=0.25 ; \sigma^{E, D}=0.05$ : $u^{E, D}=1.05, p^{u p}=0.245 ; \sigma^{E, D}=0.15: u^{E, D}=$ $1.16, p^{u p}=0.23 ; \sigma^{E, D}=0.25: u^{E, D}=1.28$, $p^{u p}=0.22 ; \sigma^{E, D}=0.35: u^{E, D}=1.42, p^{u p}=0.205 ;$ $\sigma^{E, D}=0.45: u^{E, D}=1.56, p^{u p}=0.195$.

\section{Acknowledgments}

We would like to thank the anonymous referees and the department editor Karl Inderfurth for their very helpful comments and suggestions that helped to improve the manuscript considerably.

\section{References}

Aikens, Charles H. (1985): Facility Location Models for Distribution Planning, European Journal of Operational Research, 22 (3): 263-279.

Alonso-Ayuso, Antonio, Laureano F. Escudero, Araceli Garìn, Maria T. Ortuño, and Gloria Pérez (2003): An Approach for Strategic Supply Chain Planning under Uncertainty Based on Stochastic 0-1 Programming, Journal of Global Optimization, 26 (1): 97-124.
Arntzen, Bruce C., Gerald G. Brown, Terry P. Harrison, and Linda L. Traffton (1995): Global Supply Chain Management at Digital Equipment Corporation, Interfaces, 25 (1): 69-93.

Aytekin, Umut and John R. Birge (2004): Optimal Investment and Production Across Markets with Stochastic Exchange Rates, Working paper, SSRN.

Beamon, Benita M. (1998): Supply Chain Design and Analysis: Models and Methods, International Journal of Production Economics, 55 (3): 281-294.

Bihlmaier, Ralf, Achim Koberstein, and René Obst (2009): Modeling and Optimizing of Strategic and Tactical Manufacturing Planning in the German Automotive Industry under Uncertainty, OR Spectrum, 31 (2): 311336.

Birge, John R. and Francois V. Louveaux (1997): Introduction to Stochastic Programming, Springer: New York et al., NY.

Boyer, Kenneth K. and G. Keong Leong (1996): Manufacturing Flexibility at the Plant Level, Omega, 24 (5): 495-510.

Briys, Eric and Bruno Solnik (1992): Optimal Currency Hedge Ratios and Interest Rate Risk, Journal of International Money and Finance, 11 (5): 431-445.

Broll, Udo, Jack E. Wahl, and Itzhak Zilcha (1999): Hedging Exchange Rate Risk: The Multiperiod Case, Research in Economics, 53 (4): 365-380.

Chandra, Charu, Mark Everson, and Janis Grabis (2005): Evaluation of Enterprise-Level Benefits of Manufacturing Flexibility, Omega, 33 (1): 17-31.

Chen, Sheng-Syan, Cheng-Few Lee, and Keshab Shrestha (2003): Futures Hedge Ratios: A Review, The Quarterly Review of Economics and Finance, 43 (3): 433-465.

Chen, Zhi-Long, Shanling Li, and Devanath Tirupati (2002): A Scenario-Based Stochastic Programming Approach for Technology and Capacity Planning, Computers \& Operations Research, 29 (7): 781-806.

Chod, Jiri, Nils Rudi, and Jan A. Van Mieghem (2010): Operational Flexibility and Financial Hedging: Complements or Substitutes?, Management Science, 56 (6): 1030-1045.

Cohen, Morris A. and Arnd Huchzermeier (1999): Global Supply Chain Network Management under Price/Exchange rate Risk and Demand Uncertainty, in: Moreno Muffatto and Kulwant S. Pawar (eds.): Logistics in the Information Age, SGE: Padua, 219-234.

Cohen, Morris A. and Suman Mallik (1997): Global Supply Chains: Research and Applications, Production and Operations Management, 6 (3): 193-210.

Cox, John C., Stephen A. Ross, and Mark Rubinstein (1979): Option Pricing: A Simplified Approach, Journal of Financial Economics, 7 (3): 229-263. 
Ding, Qing, Lingxiu Dong, and Panos Kouvelis (2007): On the Integration of Production and Financial Hedging Decisions in Global Markets, Operations Research, 55 (3): 470-489.

Fábián, Csaba I. (2008): Handling CVaR Objectives and Constraints in Two-Stage Stochastic Models, European Journal of Operational Research, 191 (3): 888-911.

Ferber, Sonja (2005): Strategische Kapazitäts- und Investitionsplanung in der globalen Supply Chain eines Automobilherstellers, Shaker: Aachen.

Fine, Charles H. and Robert M. Freund (1990): Optimal Investment in Product-Flexible Manufacturing Capacity, Management Science, 36 (4): 449-466.

Fleischmann, Bernhard, Sonja Ferber, and Peter Henrich (2006): Strategic Planning of BMW's Global Production Network, Interfaces, 36 (3): 194-208.

Francas, David, Mirko Kremer, Stefan Minner, and Markus Friese (2009): Strategic Process Flexibility under Lifecycle Demand, International Journal of Production Economics, 121 (2): 427-440.

Froot, Kenneth A., David S. Scharfstein, and Jeremy C. Stein (1993): Risk Management: Coordinating Corporate Investment and Financing Policies, Journal of Finance, 48 (5): 1629-1658.

Garman, Mark B. and Steven W. Kohlhagen (1983): Foreign Currency Option Values, Journal of International Money and Finance, 2 (3): 231-237.

Geoffrion, Arthur M. and Glenn W. Graves (1974): Multicommodity Distribution System Design by Benders Decomposition, Management Science, 20 (5): 822-844.

Gupta, Diwakar, Yigal Gerchak, and John A. Buzacott (1992): The Optimal Mix of Flexible and Dedicated Manufacturing Capacities: Hedging Against Demand Uncertainty, International Journal of Production Economics, 28 (3): 309-319.

Hodder, James E. (1984): Financial Market Approaches to Facility Location under Uncertainty, Operations Research, 32 (6): 1374-1380.

Hodder, James E. and M. Cemal Dincer (1986): A Multifactor Model for International Plant Location and Financing under Uncertainty, Computers \& Operations Research, 13 (5): 601-609.

Hodder, James E. and James V. Jucker (1985a): International Plant Location under Price and Exchange Rate Uncertainty, Engineering Costs and Production Economics, 9 (1-3): 225-229.

Hodder, James E. and James V. Jucker (1985b): A Simple Plant Location Model for Quantity-Setting Firms Subject to Price Uncertainty, European Journal of Operational Research, 21 (1): 39-46.

Huchzermeier, Arnd and Morris A. Cohen (1996): Valuing Operational Flexibility under Exchange Rate Risk, Operations Research, 44 (1): 100-113.
Hull, John C. (2003): Options, Futures and Other Derivatives, $5^{\text {th }}$ ed., Prentice Hall: Upper Saddle River, NJ.

Jordan, William C. and Stephen C. Graves (1995): Principles on the Benefits of Manufacturing Process Flexibility, Management Science, 41 (4): 577-594.

Jucker, James V. and Robert C. Carlson (1976): The Simple Plant-Location Problem under Uncertainty, Operations Research, 24 (6): 1045-1055.

Kazaz, Burak, Maqbool Dada, and Herbert Moskowitz (2005): Global Production Planning under ExchangeRate Uncertainty, Management Science, 51 (7): 11011119.

Klose, Andreas and Andreas Drexl (2005): Facility Location Models for Distribution System Design, European Journal of Operational Research, 162 (1): 4-29.

Kouvelis, Panos (1999): Global Sourcing Strategies under Exchange Rate Uncertainty, in: Sridhar Tayur, Ram Ganeshan, and Michael Magazine (eds.): Quantitative Models for Supply Chain Management, Springer US: New York et al., NY, 625-667.

MirHassani, Seyyed Ali, Cormac Lucas, Gautam Mitra, Enza Messina, and Chandra A. Poojari (2000): Computational Solution of Capacity Planning Models under Uncertainty, Parallel Computing, 26 (5): 511-538.

Musiela, Marek and Marek Rutkowski (1997): Martingale Methods in Financial Modeling, Springer: Berlin.

Owen, Susan H. and Mark S. Daskin (1998): Strategic Facility Location: A Review, European Journal of Operational Research, 111 (3): 423-447.

Rockafellar, Ralph T. and Stanislav Uryasev (2002): Conditional Value-At-Risk for General Loss Distributions, Journal of Banking and Finance, 26 (7): 14431471.

Santoso, Tjendera, Shabbir Ahmed, Marc Goetschalckx, and Alexander Shapiro (2005): A Stochastic Programming Approach for Supply Chain Network Design under Uncertainty, European Journal of Operational Research, 167 (1): 96-115.

Valente, Christian, Gautam Mitra, Mustapha Sadki, and Robert Fourer (2009): Extending Algebraic Modelling Languages for Stochastic Programming, Journal on Computing, 21 (1): 107-122.

Vidal, Carlos J. and Marc Goetschalckx (1997): Strategic Production-Distribution Models: A Critical Review with Emphasis on Global Supply Chain Models, European Journal of Operational Research, 98 (1): 1-18.

$\mathrm{Wu}$, Jason and Suvrajeet Sen (2000): A Stochastic Programming Model for Currency Option Hedging, Annals of Operations Research, 100 (1-4): 227-249.

Zhu, Wanshan and Roman Kapuscinski (2006): Optimal Operational Versus Financial Hedging for a Risk-Avers Firm, Working paper, University of Michigan. 


\section{Biographies}

Achim Koberstein is Professor and holds the DetlefHuebner-Chair in Logistics and Supply Chain Management at Goethe-University Frankfurt, Germany. He studied Computer Science at the University of Paderborn and the Georgia Institute of Technology, Atlanta, USA. In 2005 he received his doctorate from the University of Paderborn. His research interests include optimization models and systems for production planning, supply chain management and for the liberalized gas market as well as optimization algorithms and solver technology in linear and stochastic optimization.
Elmar Lukas is Professor and holds the Chair in Financial Management and Innovation Finance at Otto-vonGuericke University Magdeburg, Germany. He studied Physics and Industrial Engineering and Management at the University of Paderborn and at the University of California, Berkeley. In 2003, he received his doctorate from the University of Paderborn, where he also achieved his habilitation in 2008. His research interests include corporate finance, option pricing, mergers and acquisitions, and industrial economics.

Marc Naumann was a doctoral student at the Decision Support and Operations Research Lab of the University of Paderborn starting in 2009 and completed his $\mathrm{PhD}$ in 2012. His main research interests include airline scheduling, scheduling in public transport, stochastic optimization, robust optimization and risk management. 